OPEN ACCESS

Edited by:

Dipnarine Maharaj,

Maharaj Institute of Immune

Regenerative Medicine, United States

Reviewed by:

Takashi Nagasawa,

Osaka University, Japan Jonilson Berlink Lima,

Federal University of Western Bahia,

Brazil

Roi Gazit,

Ben Gurion University of the Negev,

Israel

*Correspondence:

Milica Perišić Nanut

milica.perisic@ijs.si

Specialty section:

This article was submitted to

Cytokines and Soluble

Mediators in Immunity,

a section of the journal

Frontiers in Immunology

Received: 13 March 2021

Accepted: 01 July 2021

Published: 15 July 2021

Citation:

Perišić Nanut M, Pečar Fonović U, Jakoš $T$ and Kos J (2021) The Role of Cysteine Peptidases in

Hematopoietic Stem Cell

Differentiation and Modulation of

Immune System Function.

Front. Immunol. 12:680279

doi: 10.3389/fimmu.2021.680279

\section{The Role of Cysteine Peptidases in Hematopoietic Stem Cell Differentiation and Modulation of Immune System Function}

\author{
Milica Perišić Nanut ${ }^{1 *}$, Urša Pečar Fonović ${ }^{2}$, Tanja Jakoš ${ }^{2}$ and Janko Kos ${ }^{1,2}$ \\ ${ }^{1}$ Department of Biotechnology, Jožef Stefan Institute, Ljubljana, Slovenia, ${ }^{2}$ Faculty of Pharmacy, University of Ljubljana, \\ Ljubljana, Slovenia
}

Cysteine cathepsins are primarily involved in the degradation and recycling of proteins in endo-lysosomal compartments but are also gaining recognition as pivotal proteolytic contributors to various immune functions. Through their extracellular proteolytic activities within the hematopoietic stem cell niche, they are involved in progenitor cell mobilization and differentiation. Cysteine cathepsins, such as cathepsins $L$ and $S$ contribute to antigeninduced adaptive immunity through major histocompatibility complex class II antigen presentation whereas cathepsin $\mathrm{X}$ regulates $\mathrm{T}$-cell migration. By regulating toll-like receptor signaling and cytokine secretion cysteine cathepsins activate innate immune cells and affect their functional differentiation. Cathepsins $\mathrm{C}$ and $\mathrm{H}$ are expressed in cytotoxic T lymphocytes and natural killer cells and are involved in processing of progranzymes into proteolytically active forms. Cytoplasmic activities of cathepsins B and L contribute to the maintenance of homeostasis of the adaptive immune response by regulating cell death of $\mathrm{T}$ and $\mathrm{B}$ lymphocytes. The expression pattern, localization, and activity of cysteine cathepsins is tightly connected to their function in immune cells. Furthermore, cysteine cathepsins together with their endogenous inhibitors, serve as mediators in the interplay between cancer and immune cells that results in immune cell anergy. The aim of the present article is to review the mechanisms of dysregulation of cysteine cathepsins and their inhibitors in relation to immune dysfunction to address new possibilities for regulation of their function.

Keywords: cysteine cathepsins, cystatins, hematopoietic stem cell, immune cell development, extralysosomal activity

\section{INTRODUCTION}

Lysosomes are single-membrane degradative organelles that are essential for cell homeostasis. Through proteolytic processing and degradation, lysosomes are involved in numerous cellular processes. Cathepsins constitute a subset of lysosomal peptidases and, according to their catalytic type, are classified as serine (A and G), aspartic (D and E; pepsin family A1A), or cysteine (B, C, L, F, $\mathrm{H}, \mathrm{K}, \mathrm{O}, \mathrm{S}, \mathrm{V}, \mathrm{X}$, and W; papain family C1A) cathepsin peptidases (1). Cysteine cathepsins gained 
much attention in the past decades due to the critical role they play in cellular compartments other than those of the endolysosomal system and within the extracellular milieu (2). Apart from their important roles in the immune response, such as antigen processing and presentation as well as processing and activating various proteins and hormones, cysteine cathepsins also play important roles in immune cell development, regulation of the immune response and immune homeostasis, and aging of the immune system.

The majority of cysteine cathepsins are ubiquitous; however, the cellular expression patterns of some are strictly linked to their biological function $(3,4)$. Cathepsin $\mathrm{K}$ (CatK) is abundant in osteoblasts, osteoclasts, macrophages, synovial fibroblasts, and epithelial cells (5), cathepsin V (CatV) expression is restricted to the thymus and testis (6), and cathepsin S (CatS) is expressed in antigen-presenting cells (APCs) such as B cells and dendritic cells (DCs) (7). The highest expression of cathepsin X (CatX) is detected in immune cells of myeloid lineage such as macrophages, DCs, and microglia; however, its expression was also detected in B lymphocytes and natural killer (NK) cells (8, 9). Cathepsin W is limited to cytotoxic lymphocytes, with significantly higher expression levels in NK cells than those in cytotoxic T lymphocytes (CTLs) (10).

As peptidases catalyze the irreversible cleavage of peptide bonds, any dysregulation in peptidase expression, localization, or proteolytic activity can disrupt cellular homeostasis. Their activity is regulated through the regulation of gene expression, posttranslational modifications, activation of zymogens, the accessibility of the susceptible peptide bond in the substrate, their compartmentalization, and their endogenous inhibitors $(11,12)$. Dysregulated cathepsin activity was shown to be the contributing factor in diseases such as bronchial asthma, atherosclerosis, rheumatoid arthritis, osteoarthritis, and cancer (13).

In this review, we focus primarily on lysosomal and extralysosomal cysteine cathepsins and their role in the development of the immune system and in the regulation of the immune response. A comprehensive review of the role of cysteine cathepsins in myeloid cell differentiation and function was published by our group recently (14) therefore our aim is to highlight the recent developments in the field and emphasize the importance of cysteine peptidases and their endogenous and exogenous inhibitors for normal development, function and homeostasis of the lymphoid cells of the immune system.

\section{THE STRUCTURE AND LOCALIZATION OF CYSTEINE CATHEPSINS}

\section{Structure}

Due to their structural similarity to the plant cysteine peptidase papain, isolated from Carica papaya in 1937, cysteine cathepsins were designated as the $\mathrm{C} 1$ family, clan $\mathrm{CA}$ of the MEROPS peptidase classification system $(15,16)$. Papain-like peptidases are composed of the N-terminal left domain, which contains three $\alpha$ helices, and the C-terminal right domain, which forms the $\beta$-barrel fold. At the interface of both domains lies the $\mathrm{V}$ shaped active site cleft that includes the conserved catalytic pair
Cys-His. Cathepsins are monomeric proteins with an average molecular weight of $20-35 \mathrm{kDa}$ in their mature form; the only exception is cathepsin C (CatC; also named dipeptidylpeptidase I or DPPI) that exists as a $200 \mathrm{kDa}$ homotetramer (17-19).

Cathepsins are synthesized as precursor preproenzymes and are shuttled to the endoplasmic reticulum, where their $\mathrm{N}$-signaling sequence is cleaved, and the protein is N-glycosylated. Highmannose glycans are essential for binding to mannose 6phosphate receptors, packaging into clathrin-coated vesicles, and sorting to lysosomes. In addition, lysosomal hydrolases can be sorted in mannose 6-phosphate receptor-independent pathways $(20,21)$. The active site of cathepsin zymogens is blocked by the $\mathrm{N}$ terminal proregion, which acts as a reversible inhibitor to prevent premature enzyme activation while also containing sorting signals and assisting in correct folding. Conversion to the mature form takes place in the acidic and reducing milieu of lysosomes, in which the propeptide is cleaved either via autocatalytic processing or transactivation by another peptidase (22). In an additional proteolytic step, the cathepsins $\mathrm{B}, \mathrm{H}$, and $\mathrm{L}$ can be processed from a single chain to disulfide-linked heavy and light chains, without the loss of their activity (23). With few exceptions, cathepsins are endopeptidases. Exopeptidases exhibit additional structural features that restrict access to the active site and form electrostatic bonds with the C- or $\mathrm{N}$-termini of substrates (24).

Cathepsins have relatively small substrate binding area, which encompasses the S1, S2, and S1' binding pockets. The remaining active-site subsites (S3 and S2') are less structurally defined and do not depend on main chain interactions with the substrate. Substrate binding mainly depends on the characteristics of the P2 substrate residue $(25,26)$ and several studies have demonstrated a strong preference of cysteine cathepsins for small hydrophobic amino acid residues (Leu, Val, Ile) in the P2 position of the substrate (27). Although cathepsins have broad and partially overlapping substrate specificities there are several examples of higher substrate specificity. For example, $\beta 2$ cytoplasmic tail of integrin $(28,29)$ and profilin 1 were validated as a CatX targets (30), whereas $\mathrm{CatH}$, as a monoaminopeptidase, processes talin at its N-terminal head domain that contains the integrin binding site (31). There are also examples of substrates like collagen, osteocalcin, cytokines, and chemokines, which were only cleaved by a subset of cathepsins $(27,32)$.

\section{Localization}

The endo-lysosomal internal acidic $\mathrm{pH}$ favors cathepsin activity and induces conformational changes in the substrates, leading to their proteolytic cleavage by cathepsins (33). However, cysteine cathepsins can be found in cellular compartments other than endo-lysosomes and also in the extracellular space (27) (Figure 1). Kinetic studies in vitro showed that irreversible unfolding occurs at neutral $\mathrm{pH}$ for all cathepsins (34), except for the more stable CatS (35). However, binding to their substrates or endogenous inhibitors (36) as well as allosteric interactions with glycosaminoglycans (GAGs) and other negatively charged molecules (37) stabilize cysteine cathepsins and preserve their activity even at higher $\mathrm{pH}$ outside endolysosomes. Several studies showed interdependence between cysteine cathepsins and GAGs [reviewed in (37)]. Cysteine 


\section{A Extracellular proteolysis}

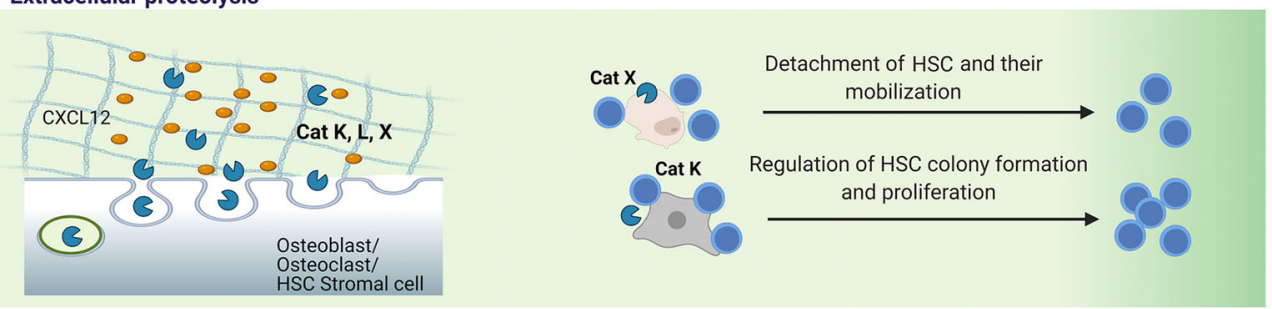

B Lysosomal proteolysis

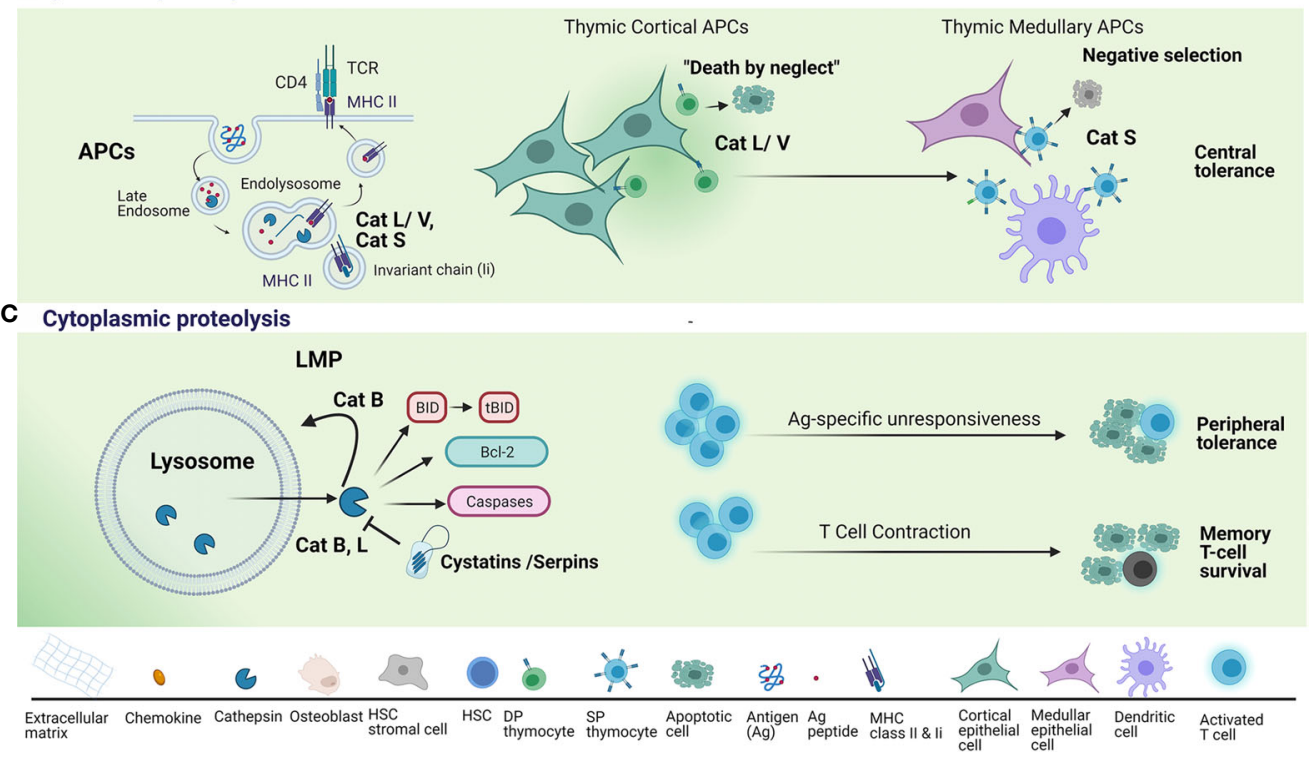

FIGURE 1 | Regulation of T lymphocyte survival by cysteine cathepsins. (A) When secreted into the extracellular space, cysteine cathepsins, such as cathepsin $\mathrm{K}$ (Cat K), cathepsin L (Cat L) and cathepsin X (Cat X) remodel extracellular matrix (ECM) and degrade chemokines, such as C-X-C motif chemokine 12 (CXCL12), necessary for hematopoietic stem cells (HSCs) proliferation and their retention within the HSC niche. This leads to detachment of HSCs and their mobilization from the HSC niche. Lack of Cat K within the niche microenvironment results in reduced proliferation of HSC and their cell colony formation and proliferation.

(B) Endolysosomal cysteine cathepsins are essential for two steps in major histocompatibility complex (MHC) class II antigen presentation: (a) the degradation of invariant chain (li) to class II-associated invariant chain peptide (CLIP) to permit dissociation of CLIP from class II molecules and subsequent peptide binding; and (b) the generation of antigenic peptide fragments from larger polypeptide/protein moieties. Cat $\mathrm{L}$, in mouse cortical thymic antigen presenting cells (APC) and cathepsin $\mathrm{V}$ (Cat V) in human APC, have non-redundant roles in degradation of invariant chain (li) to class II-associated invariant chain peptide (CLIP). Cathepsin S (Cat S) is involved in MHC class II antigen presentation in medullary thymic APCs. Thymocyte, whose T-cell receptor (TCR) fails to recognize an antigenic peptide/MHC complex on cortical APCs, fails to receive a survival signal i.e. death by neglect. Thymocytes, whose TCR strongly binds to antigenic peptide/MHC complex on medullary APCs are eliminated i.e. negative selection. (C) Following the induction of apoptosis, lysosomal cathepsins are released from lysosomes through lysosomal membrane permeabilization (LMP). Cathepsins B (Cat B) and L perform their pro-apoptotic function in the cytosol by cleaving Bid, a pro-apoptotic Bcl-2 family member, anti-apoptotic Bcl-2 family protein or cleaving and directly activating caspases. Cysteine peptidase inhibitors, such as serpins and cystatins, may regulate cathepsin activity in the cytosol. Cat B further promotes LMP and the release of lysosomal constituents. Cathepsins B and L released through LMP have been implicated in apoptosis triggered by supraoptimal activation of T lymphocytes i.e. high dose tolerance. Cat B pro-apoptotic actions in the cytosol have been shown to mediate apoptosis induction upon critical phase of immunity whereby the vast majority of effector T cells die by apoptosis i.e. T cell contraction. Upregulation of endogenous inhibitor (Spi) 2A enables survival of memory T cells; antigen (Ag).

cathepsins are capable of cleaving proteoglycan core proteins and thereby release GAGs; in turn GAGs affect both the activity and stability of cysteine cathepsins in the extracellular space (37). In addition, acidification of the cytosol observed under certain conditions such as apoptosis enables cathepsins to mediate key physiological processes $(38,39)$.

Cells of hematopoietic origin, such as platelets, neutrophils, eosinophils, mast cells, macrophages, and cytotoxic cells, contain a specialized lysosomal compartment that can be secreted into the extracellular environment in response to specific stimuli $(27,40$,
41). These "secretory lysosomes" include cytotoxic granules, major histocompatibility (MHC) class II compartments, and basophil and azurophil granules (42). Like conventional lysosomes, secretory lysosomes contain degradative proteins and similar internal acidic $\mathrm{pH}$ but are distinguished by their ability to undergo controlled secretion (43). In this fashion, multiple aspects of the immune response are regulated through extracellular proteolysis by cysteine cathepsins. For example, CatX translocation from lysosomes to the perimembrane region facilitates migration of immune cells and depends on the interaction of CatX with the cytoplasmic tails of $\beta_{2}$ 
integrin receptors $(28,44)$. After vesicular exocytosis, cathepsins can be delivered to the cell membrane, where they associate with components of the extracellular matrix (ECM) or remain adhered to the membrane, as was shown for cathepsins B, S, and X. CatB localizes to the cell membrane by binding to surface annexin II ( 45 , 46), whereas cathepsins $S$ and X interact with $\alpha_{v} \beta_{3}$ integrins (47, 48). Likewise, osteoclasts reorganize their lysosomal compartment by translocating lysosomal glycoproteins and proton pumps to the ruffled border membrane to secrete lysosomal enzymes at the site of bone resorption (49).

Apart from vesicular exocytosis, different stimuli promote lysosomal release of cathepsins and their translocation to other cellular compartments (27). Namely, cathepsins have also been detected in cell nuclei, in which they are involved in the regulation of gene expression and the cell cycle (50). Cathepsins without nuclear localization motifs rely on chaperone molecules (such as Snail and HLA B-associated transcript 3) for translocation, which are often enhanced in cancer cells $(51,52)$. In the nucleus, cathepsins degrade the regulators of nuclear DNA repair machinery, including BRCA1 [cathepsins B (53) and S (54)] and 53bpl (cathepsin L) (55).

In the past two decades, it was shown that by regulating apoptosis in immune cells, cathepsins play important roles in the development, maturation, and function of lymphocytes. For their proapoptotic function, cathepsins must be released from lysosomes into the cytosol by lysosomal membrane permeabilization (LMP) (56) (Figure 1). Unlike lysosomal rupture, which results in necrosis, LPM results in a slow release of cathepsins and the selective cleavage of a few targets. LMP is induced by a plethora of stimuli including oxidative stress, lysosomotropic agents, and certain endogenous cell death receptors. The cytosolic cathepsins B, D, and L indirectly support activation of caspase-dependent apoptosis by promoting mitochondrial membrane destabilization through cleavage of the pro-apoptotic $\mathrm{BH} 3$-only protein, Bid, and degradation of the B-cell lymphoma-2 protein, Bcl-2 $(57,58)$. Simultaneously, cathepsins are involved in the degradation of the anti-apoptotic proteins Bcl-2, Bcl-xL, Mcl-1, and XIAP (X-linked inhibitor of apoptosis), thus promoting apoptosis (59). Furthermore, CatB amplifies the feedback loop by potentiating the extent of LMP (60). Cathepsins also modulate other cell death pathways, mostly detected in immune cells, including programmed necrosis, i.e., necroptosis. Necroptosis is initiated by various stimuli and requires the kinase activity of receptor-interacting serine/ threonine kinase 1 . In macrophages, cathepsins $\mathrm{B}$ and $\mathrm{S}$ cleave receptor-interacting protein kinase 1 and thus limit necroptosis (61). CatB is responsible for the proinflammatory response during lytic programmed cell death, i.e., pyroptosis, as it activates the NLR family pyrin domain containing 3 (NLRP3) NLRP3 inflammasome and caspase- 1 that catalyze the production of the interleukins (IL) IL$1 \beta$ and IL-18 (62).

\section{CYSTEINE CATHEPSINS IN IMMUNE CELL DEVELOPMENT AND DIFFERENTIATION}

Hematopoietic stem cells (HSCs) are retained and regulated in specialized perivascular niches consisting of various support cells such as endothelial cells, osteoblasts, macrophages, megakaryocytes, perivascular cells, and specialized reticular cells (63). The complex microenvironment of the HSC niche enables HSC maintenance, proliferation, and differentiation into mature blood and immune cells (63). During embryogenesis in both mice and humans, hematopoiesis occurs in multiple waves throughout the developing embryo and fetus, including the aorta-gonad-mesonephros, fetal liver, and placenta before HSC eventually homing to the bone marrow $(\mathrm{BM})(64,65)$.

\section{Lymphoid Organs}

While there are multiple studies implicating cysteine cathepsins in the regulation of bone ECM homeostasis $(2,66)$, very little is known about their involvement in hematopoiesis and the maintenance of the HSC niche ECM. The ECM of the HSC niche contains structural collagens, fibronectin, laminin, and proteoglycans and is a rich reservoir of local growth factors, cytokines, and other bioactive molecules (63). Multiple components of this niche ECM are similar to the components of bone ECM and are subject to regulation by the same peptidases and their natural inhibitors (Table 1). For example, CatK is known to degrade type I collagen that is critical for osteoclast bone resorptive activity (85); however, type I collagen was also found to be required for the optimal survival of HSCs (86). Furthermore, various cysteine cathepsins were shown to cleave the protein core of proteoglycan, a major constituent of the ECM. Proteoglycans such as heparan sulfate are implicated as critical components of the HSC niche (87), and the inhibition of heparan sulfate proteoglycan production by BM osteolineage stromal cells results in HSC egress from the BM niche into the peripheral circulation (67). Another protein that is tightly involved in the regulation of ECM homeostasis and is a substrate of cathepsins is heparanase, an endo- $\beta$-D-glucuronidase that degrades GAGheparan sulfate in the ECM. Cathepsin L (CatL) is essential for the activation of heparanase (88). Several other ECM substrates of CatK, such as stem cell factor, osteopontin, and the chemokine SDF-1 (also called CXCL12) all have documented effects on HSCs and important for HSC maintenance $(89,90)$.

Osteoblasts represent the major cell type of the HSC niche. Although the role of osteoblasts in supporting HSCs was shown to be more limited than previously expected [reviewed in more detail in (91)], they play an important role in immune regulation through secreting biologically active molecules that maintain the BM microenvironment and factors such as CXCL-12 necessary for stem cell maintenance (90) (Figure 1). Osteoblasts represent a rich reservoir of cathepsins and were shown to secrete proteolytically active cysteine cathepsins, such as cathepsins B, $\mathrm{K}, \mathrm{L}$, and X (68). All of these cathepsins were shown to digest the chemokine CXCL12, a key mediator that retains hematopoietic progenitor cells in their niches (69). Furthermore, only CatX can inhibit adhesive interactions between $\mathrm{CD} 34^{+}$hematopoietic progenitor cells and osteoblasts (70) (Figure 2). Interestingly, whereas CatX is preferentially expressed by mature cells of the hematopoietic and immune system, it is not synthesized by hematopoietic progenitor cells (70).

Osteoclasts are derived from the same myeloid precursor cells that give rise to macrophages and myeloid DCs. Their differentiation is marked by increased CatK expression and 
TABLE 1 | The role of cysteine cathepsins in immune cell development and homeostasis.

\section{Immune cell development}

Bone Osteoblast (67) secreted Cathepsin K degrades type I collagen (60), osteopontin, and CXCL12 (65).

marrow Cathepsins $B, L$, and X digest CXCL12 in vitro (67).

Cathepsin $L$ is involved in activation of heparanase (64).

Cathepsin $\mathrm{K}$ is required for osteoclast engagement in response to the microenvironmental stimuli (59).

Cathepsin K derived from HSC supportive stromal cells $(68,69)$ affects LSK cell colony formation and proliferation in vitro and their repopulating activity and maintenance of lymphopoiesis in vivo (70).

In vitro, TLR9 signaling promotes caspase-independent cell death via a cathepsin B-dependent mechanism in pro-B cells (71).

Thymus Cathepsin L is critical MHC class II-mediated peptide presentation, acting both in li degradation (72) and in the generation of MHC class II-bound peptide ligands presented by thymic cortical APCs in mice (73).

Cathepsin V expressed in thymic cortical APCs in human thymus, participates in li processing (74)

Cathepsin S in human thymic DCs, is involved in negative selection/elimination of autoreactive T cells (75).

Cathepsin $\mathrm{L}$ is critical for CD1d presentation to NKT cells in vitro and their selection in vivo (76).

Cathepsin $L$ is critical for maturation of NKT cells (77).

\section{Immune cell homeostasis}

Cathepsins B and L activities are essential for T lymphocyte apoptosis in response to high concentration of antigen in vitro (78, 79).

Cathepsin B pro-apoptotic activity limits the long-term maintenance of memory CD8+ T cell populations (80).

Cathepsins B and $L$ are essential for antigen-dependent germinal center B cell death (81).

Cathepsin B was identified as a negative feedback regulator of lysosomal biogenesis and autophagy (82).

Cathepsin $\mathrm{H}$, trough cleavage of talin (30) could be involved in maintaining the homeostasis and survival of the regulatory $\mathrm{T}$ (Treg) cell pool (83).

Pro- and mature forms of cathepsin X interact with $\beta 2$ integrin receptors, thus modulating their affinity for extracellular ligands (84).

CXCL12, C-X-C motif chemokine 12; HSC, Hematopoietic stem cells; NKT, Natural killer T cells; TLR9, Toll-like receptor 9; MHC, major histocompatibility complex molecules; li, invariantchain; APC, antigen presenting cell; LSK Lineage-Sca ${ }^{+}$Kit ${ }^{+}$cells; dendritic cells; (DCs), dendritic cells.

\section{Cysteine Cathepsins in T-cell Immunity}

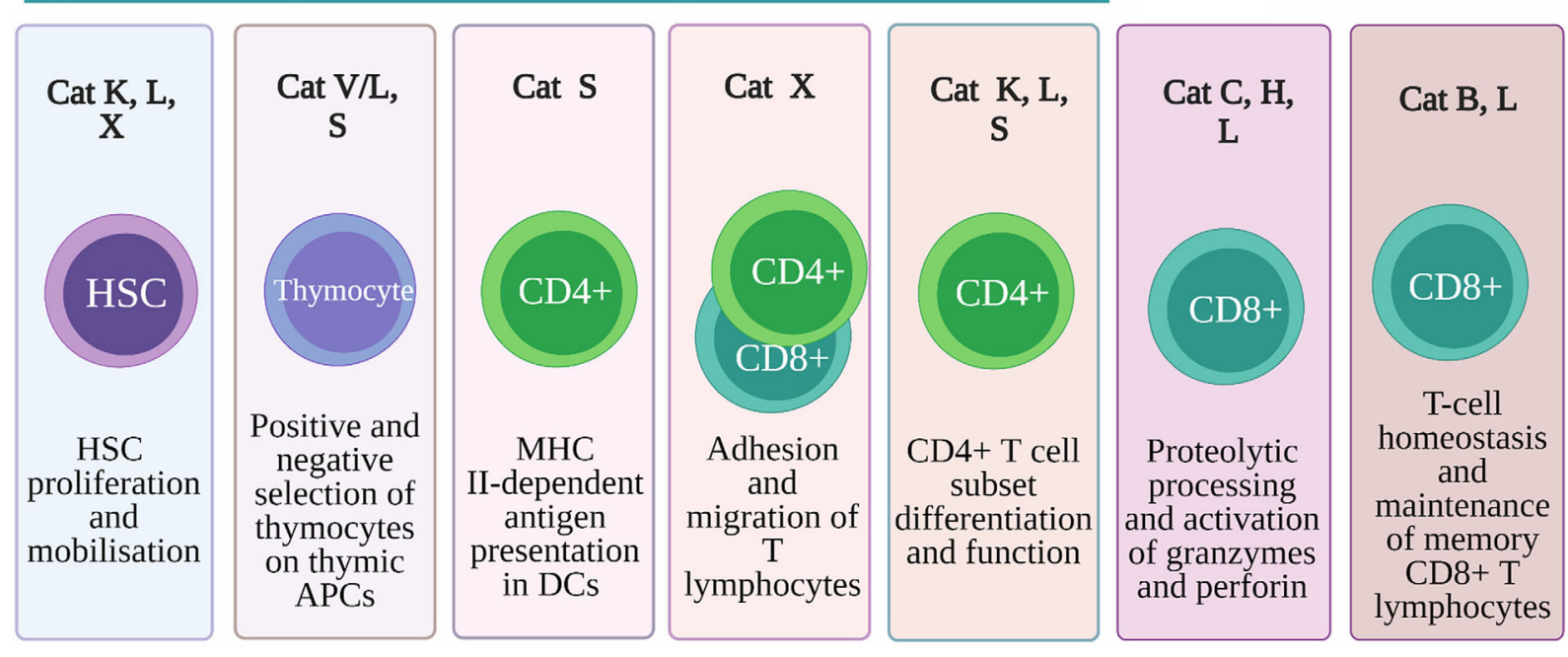

FIGURE 2 | Role of Cysteine Cathepsins in T-cell immunity. Despite their overlapping substrate specificities several cysteine peptidases have been shown to play non-redundant roles in development, function and homeostasis of T cells. Cathepsin K (Cat K), cathepsin L (Cat L) and cathepsin X (Cat X) are involved in remodeling of extracellular matrix (ECM) and degradation of chemokines, necessary for hematopoietic stem cells (HSCs) proliferation and retention within the HSC niche. Cat L, in mouse cortical thymic antigen presenting cells (APC) and cathepsin V (CatV) in human APC, are indispensable for degradation of invariant chain (Ii) to class II-associated invariant chain peptide (CLIP) necessary for the process of positive thymic selection. In human professional APCs cathepsin S (Cat S) was shown to be indispensable for MHC class II antigen presentation. By regulating toll-like receptor (TLR) 9 and TLR7 signaling in dendritic cells (DC) CatK affects Th17 polarization. Cathepsin S (CatS), through activation DC protease-activated receptor-2 (PAR2) and upregulation of IL-6 secretion drives splenic DC-dependent Th17 differentiation. Cat K through cleavage of TLR7 blocks immuno-suppressive activity regulatory $T$ cells (Tregs). Through processing of $\beta 2$ integrin receptors Cat $X$ modulates their affinity for extracellular ligands thus affecting the adhesion and migration of $\mathrm{T}$ lymphocytes. Cat $\mathrm{C}$ and cathepsin $\mathrm{H}$ $($ Cat $H)$ are involved in proteolytic processing and activation of granzymes, main effector molecules of CD8+ cytotoxic lymphocytes whereas Cat $L$ has been implicated in processing and activation of perforin. 
downregulated expression of cathepsins B, L, and X (92). Compared to wild-type $(w t)$ mice, CatK $(-/-)$ mice exhibited significantly increased numbers of committed $\mathrm{CD} 11 \mathrm{~b}(+)$ osteoclast precursors in the $\mathrm{BM}$, whereas the percentage, but not the number of these cells, was decreased in the spleen (93). Additionally, osteoclast precursors lacking CatK fail to migrate and engraft in a fracture wound during injury repair, indicating that CatK is also required for osteoclast engagement in response to microenvironmental stimuli (66). Increased CatK expression in mouse leads to increased osteoclast formation from BM precursors in vitro (71). Initial studies on mice with CatK deficiency demonstrated abnormalities in hematopoietic compartments, decreased BM cellularity, and splenomegaly (66). A later study showed that a CatK deletion in mice resulted in reduced numbers of immature lineage-SCA1+KIT+ (LSK) cells and mature Ly6Clow and CD11c+ cells in BM (93). However, until recently, the physiological role of CatK in stromal cells of the HSC niche, other than osteoclasts, has not been explored. Stromal cells that maintain HSCs during in vitro culture show high transcription of the CatK gene. Although no effects of CatK loss on early hematopoiesis or myelopoiesis were detected in vivo, in vitro cultivation of LSK cells on the CatK-deficient HSC supportive stromal cell line UG26-1B6 $(94,95)$ lead to reduced colony formation and proliferation and increased differentiation to myeloid progenitors (96). The subsequent transfer of LSK cells generated in a CatK-deficient microenvironment into $w t$ mice revealed reduced donor LSK repopulating activity and lymphopoiesis maintenance (96). Further transplantation experiments revealed that environmental CatK is particularly important for the optimal regeneration of B- and Tlymphocyte compartments in different hematopoietic tissues. The most pronounced changes were detected in T lymphopoiesis in BM, implying that early $\mathrm{T}$-cell development critically depends on CatK (96).

In addition to CatK, its closely related member of the papain family, CatL, has also been shown to regulate lymphopoiesis in BM. CatL deficiency was shown to affect B-cell production by acting both on BM stem cells and BM B-cell precursors (72). Compared to $w t$ mice, mice with CTSL gene mutations (73) exhibited unaltered percentages and absolute numbers of pre-pro- $\mathrm{B}$, pro- $\mathrm{B}$, pre- $\mathrm{B}$, and immature and mature $\mathrm{B}$ cells in $\mathrm{BM}$ but increased $\mathrm{B}$-cell production and emigration from BM, leading to increased peripheral B-cell numbers (72). These data implicate CatL as a negative regulator of $\mathrm{BM}$ B-cell production and output, therefore influencing the homeostasis of peripheral B cells. Furthermore, in BM, pro-B cells are continuously produced and die unless they express pre- $\mathrm{B}$ cell receptor (pre-BCR) (74). One of the proposed mechanisms of removing pro-B cells carrying non-productive variable (V), joining $(\mathrm{J})$, and diversity (D) gene $[\mathrm{V}(\mathrm{D}) \mathrm{J}]$ rearrangement is through Toll-like receptor (TLR)-9 expressed in cells of the innate immune system as well as in B lymphocytes and their progenitors (97). TLR9 signaling directly inhibits the expansion of pro-B cells via a CatB-dependent mechanism that promotes caspaseindependent cell death (97). This regulatory mechanism is proposed to regulate lymphopoiesis in vivo and to participate in the homeostatic control of precursor compartments.

Cathepsins are most known for their involvement in degrading antigens (endocytosed as well as endogenous antigens) to antigen peptides that bind to the MHC II. A precondition for this to happen is the degradation of the invariant chain (Ii) chaperone that is associated with $\mathrm{MHC}$ class II molecules; this is also achieved by cathepsins (98). The Ii chaperone associates with MHC class II molecules immediately after their synthesis in the endoplasmic reticulum; the complex is then transported to endosomes and lysosomes in which it comes into contact with degraded antigens (99). Once bound to MHC class II molecules, antigen peptides are transferred to the membrane of APCs (100). The involvement of CatL in thymic CD4+ T-cell positive selection has been well documented (Figure 1). CatL is critical for MHC class IImediated peptide presentation in thymic epithelial cells, acting both in Ii degradation (101) and in the generation of MHC class II-bound peptide ligands presented by cortical thymic epithelial cells (102). Consequently, CatL-deficient mice exhibit impaired CD4+ T-cell selection, an altered repertoire of CD4+ lymphocytes, and an increased number of CD8+ lymphocytes (102). Cat V, that shares $80 \%$ protein sequence identity with Cat $\mathrm{L}$ is exclusively expressed in the thymic cortex in humans and it is proposed to have overtaken the role of Cat $\mathrm{L}$ in the positive selection of thymocytes (Figure 2). This is further supported by its ability to selectively degrade Ii complexed to MHC (103). Mice with the mutated CTSL gene (73) exhibit hypertrophied lymph nodes with normal absolute numbers of CD4+ and increased numbers of CD8+ lymphocytes (104). In the same way as Cat $\mathrm{K}$, a proportion of CatL is physiologically secreted and can be extracellularly activated (76) after which it can process several ECM proteins, such as fibronectin, laminin, elastin, and collagen types I, IV, and XVII (76, 77, 105-107). Furthermore, ECM components have been shown to transduce survival signals (108) and promote the proliferation of lymphocytes by signalling through integrins (109). By regulating the level of expression of ECM components in lymphoid organs, CatL can have a broad effect on immune system (104). In lymph nodes of CatL-deficient mice ECM components such as laminin, fibronectin, collagen I and IV were found to be increased. Furthermore, enlarged lymph nodes (LN) from mice with mutated CTSL gene (73) contained increased numbers of mature B cells due to their higher input into the LN (72). Apart from being a key regulator of classical MHC II antigen presentation in the thymus, CatL is also essential for nonclassical CD1d presentation (110). The absence of CatL expression in thymocytes abrogates their capacity to stimulate autoreactive NKT cells in vitro and precludes their selection in vivo (110). Furthermore, the maturational transition of NKT cells requires continuous $\mathrm{T}$ cell receptor (TCR)/CD1d interactions with the components of the thymic cortex. A recent study demonstrated that key components necessary for positive NKT cell selection, such as CatL, are also required for subsequent NKT cell maturation (111).

\section{Immune Cell Subset Differentiation}

Apart from their role in $\mathrm{T}$ lymphopoiesis, cathepsins have been implicated in T-cell lineage commitment. Unlike thymocytes, two major T helper (Th1 and Th2) lineage cells do not express CatL $(112,113)$. However, in addition to being regulated by 
cytokines and transcription factors, the differentiation of CD4+ cells to Th17 cells is actively regulated by CatL in mice (113). Mouse Th17 cell differentiation in vitro was suppressed by both broad cathepsin inhibitors and CatL selective inhibitors (113). Tuomela et al. identified CSTL among genes upregulated at the early stage of Th17 cell differentiation (114). Recently, CatL was characterized as a promising marker for human Th17 cell identification (112). Furthermore, CatK regulates signaling pathways proximal to TLR9 (115) and TLR7 (116) in DCs and affects Th17 polarization. Besides CatL and CatK, CatS plays a critical role, after exposure to components of periodontal bacteria, in driving splenic DC-dependent Th17 differentiation by upregulating IL-6 through activating DC protease-activated receptor-2 (PAR2) (117) (Figure 2). Finally, CatC was also implicated in cathepsin-dependent lysosome disruption in myeloid leukocytes and Th2-associated immune response, after adjuvant treatment (118). Cathepsins have also been implicated in the regulation of the activities of $\mathrm{T}$ regulatory cells (Tregs). Apart from being involved in TLR9 and TLR7 signaling in DCs, it was recently demonstrated that CatK produces cleaved TLR7 in vitro, and in Tregs implicating CatK in blocking Treg immuno-suppressive activity and in promoting the development of murine systemic lupus erythematosus-like manifestations (119) (Figure 2).

In APCs, the alterations in cathepsin expression, activity, or localization are closely related to their maturational and functional state. The differentiation of macrophages and DCs from granulocyte/macrophage progenitors is marked by a significant surge in cathepsin expression (7, 80). Furthermore, cytokine-stimulated HSCs, which were primed either towards immunostimulatory or immunotolerant DC phenotypes, showed differential patterns of CatS expression and activity (120). Recent data indicate that cathepsins also induce the switch between two distinct functional states of macrophages. CatL and CatS were shown to support M2 (anti-inflammatory) (121, 122), whereas CatC was shown to support M1 (pro-inflammatory) macrophage polarization through FAK-triggered p38 MAPK/NF- $\kappa$ B pathway $(123,124)$.

\section{Immune Cell Homeostasis}

At the end of an immune response, the contraction of the T-cell response results in massive apoptosis with a small subset of highly specific memory cells surviving. Once the memory T-cell population has been established, its long-term maintenance depends on successful survival and homeostatic proliferation in BM. As different pathogens are encountered, memory CD8+ T-cell populations from earlier infections (which have not re-encountered antigen) decline in frequency (125). A recent study in mice showed that lysosome stability and pro-apoptotic CatB activity limits the long-term maintenance of memory CD8+ T-cell populations. The serine protease inhibitor (Spi) 2A, an anti-apoptotic cytosolic cathepsin inhibitor that is induced by IL-15 and IL-7, was found to be necessary for counteracting pro-apoptotic CatB activity for the maintenance of memory CD8+ T lymphocytes (126) (Figure 1).

Autophagy is highly regulated lysosome-dependent process necessary for homeostasis quiescent cells of the immune system (82). Namely, memory B and T cells, plasma cells and tissue resident macrophages, as well as HSCs, all require autophagy for their homeostasis (82). Cat B genetic ablation in murine Bone Marrow-Derived Macrophages (BMDM) resulted in a nearly 2fold increase in the number of lysosomes as well as in enlargement of both single membrane lysosomes and doublemembrane autophagosomes compared to wild type cells (127).These results suggested that Cat B negatively regulates lysosomal biogenesis and autophagy (Figure 2). This is at least partially achieved through degradation of lysosomal calcium channel mammalian mucolipin TRP channel 1 (TRPML1) and alteration in lysosomal calcium signaling and regulation of transcription factor EB (TFEB) activity by Cat B (127).

Furthermore, through cleavage of talin, that critically controls integrin-dependent cell migration, CatH (31) could be involved in maintaining the homeostasis and survival of the regulatory $\mathrm{T}$ (Treg) cell pool (128).

$\beta 2$ integrins in innate and adaptive immune cells are group of receptors crucially involved in leukocyte differentiation, activation/polarization, and functional activity $(84,129)$.

Pro- and mature forms of cathepsin $X$ interact with $\beta 2$ integrin receptors, thus modulating their affinity for extracellular ligands (130) (Figure 2).

\section{ENDOGENOUS CATHEPSIN INHIBITORS}

Cathepsin activity must be controlled at several levels to prevent severe tissue damage. Cathepsin expression is spatially and temporally regulated and, as mentioned above, cathepsins are expressed in the inactive form as proenzymes. After activation, endogenous protein inhibitors are important for controlling proteolysis [summarized from (131)].

Endogenous inhibitors mainly bind, reversibly or irreversibly, into the active site of the enzyme. Based on the properties of their action, they are divided between emergency and regulatory inhibitors (132). Emergency inhibitors rapidly bind peptidases into a stable complex and prevent their further action. Their concentration exceeds the amount of their target peptidase, and they are usually spatially separated from their target peptidases. They act on the peptidases that left their natural location and on peptidases released from invading microorganisms. Accordingly, regulatory inhibitors are localized with their target enzymes. Their task is not to prevent but to regulate peptidase activity. They are further divided into three types. 1) Threshold inhibitors act similarly to emergency inhibitors but with a much lower concentration. 2) Buffer type inhibitors bind quickly to the enzyme when no substrate is present and are also quickly released in the presence of the substrate. They prevent harmful proteolysis. N-terminal regions of cysteine peptidases, for example, can also act as buffer inhibitors. After removal during peptidase activation, they operate as potent reversible inhibitors of their parent enzymes and can be referred to as propeptide-like inhibitors. The proregion, by covalently binding to the $\mathrm{N}$ terminal of the mature enzyme, physically obstructs access to the active site groove. Proregions exhibit high selectivity toward their parent enzymes [summarized in (133)]. 3) Delay type inhibitors act irreversibly or pseudo-irreversibly by slowly 
binding to the peptidase after its activation. In that way, they allow peptidases to act for a certain period. The role of endogenous inhibitors is thus not only inhibiting peptidases but also regulating their stability and expression and preventing infection by inhibiting exogenous peptidases from microorganisms. Finally, endogenous inhibitors also act through ways other than peptidase inhibition (132). They belong either to the cystatin or thyropin family.

\section{Cystatins}

In the past few decades, the cystatin group of peptidase inhibitors, classified as peptidase inhibitor family I25 (134), has been reviewed many times [(135-137), to list just a few]. Here, we will thus only summarize the typical characteristics of each type, while their role in immune cell functions will be discussed in the chapter below. Cystatins are protein inhibitors that relatively non-selectively inhibit cysteine peptidases. However, they are more potent inhibitors of cysteine endopeptidase activity than exopeptidase activity [reviewed in (132)]. For example, CatX, a carboxymonopeptidase, is not inhibited by any cystatin (138). Two conserved regions are necessary for cathepsin inhibition: the central QXVXG region and the P-W pair in the C-terminal part of cystatins $(135,136)$. Cystatins are competitive inhibitors, which bind tightly and reversibly to their targets and inhibit their targets in the $\mu \mathrm{M}$ to pM range (135). In the MEROPS database, cystatins are divided into four groups based on the copies of cystatin-like sections and the presence or absence of disulfide bonds (139).

\section{Type I Cystatins (The Stefin Family)}

Stefins are single-chain proteins with molecular masses of around $11 \mathrm{kDa}$ and possess no disulfide bonds or carbohydrates. They are located intracellularly in the cytoplasm or extracellularly in body fluids. They are stable at neutral and alkaline $\mathrm{pH}$ and are also heatstable (135). In humans, stefins A (also cystatin A) and B (also cystatin B) are well known. They potently inhibit papain and cathepsins L, S, and H. Additional stefins have been characterized in mice, cattle, and pig [summarized in (136)].

\section{Type II Cystatins (The Cystatin Family)}

These cystatins are single-chain proteins with molecular masses of $13-15 \mathrm{kDa}$. They possess two disulfide bonds and are usually non-glycosylated, except for cystatins $\mathrm{F}$ and $\mathrm{E} / \mathrm{M}$, which are glycoproteins. They are present at higher concentrations mainly extracellularly in biological fluids such as seminal plasma and cerebrospinal fluid, whereas their concentrations are lower in plasma, saliva, and urine. Type II cystatin inhibition of cysteine peptidases is the strongest among the cystatins; Ki values for endopeptidase activity inhibition can reach as low as the $\mathrm{fM}$ range [reviewed in (136)]. In humans, the cystatins $\mathrm{C}, \mathrm{E} / \mathrm{M}, \mathrm{F}, \mathrm{D}$, $\mathrm{S}, \mathrm{SA}, \mathrm{N}$, and $\mathrm{SN}$ are expressed in different tissues. However, the first described cystatin was isolated from the chicken egg-white and was named chicken cystatin (140).

\section{Type III Cystatins (The Kininogen Family)}

Kininogens are single-chain multifunctional glycoproteins with molecular masses of around $120 \mathrm{kDa}$ for high molecular weight kininogen or around $68 \mathrm{kDa}$ for low molecular weight kininogen. They are stable at neutral and alkaline $\mathrm{pH}$ and are also heat stable [summarized in (135)]. They are present in mammalian plasma and secretions. They have three cystatin-like domains of which only two have inhibitory properties. They strongly inhibit papain and CatL and weakly inhibit cathepsins $\mathrm{H}$ and B (136). Besides their inhibitory activity, they are large precursors of the vasodilator kinin peptides bradykinin and kalidin, which participate in blood pressure regulation (141) and can act as antimicrobial peptides (through their fifth domain), inducing apoptosis of proliferating epithelial cells (142).

\section{Thyropins}

Thyropins (thyroglobulin type-1 domain proteinase inhibitors) are proteins with one, two, or three thyroglobulin type-1 domains that express inhibitory action toward cathepsins, mostly cysteine cathepsins (143). They are classified as peptidase inhibitor family I31 (134). The thyroglobulin type-1 domain was first identified and characterized in thyroglobulin. It possesses four or six cysteine residues and two patterns: the Q-C pattern at consensus positions $26-27$ and the $\mathrm{C}-\mathrm{W}-\mathrm{C}-\mathrm{V}$ pattern at positions 38-41. A databank search located similar domains in 29 proteins with different functions, unrelated to thyroglobulin (144). They can be either peptidase inhibitors, substrates (145), or both (146). Thyropins bind tightly and reversibly to cysteine peptidases (147). Several thyropins have been characterized in humans: the p41 fragment of the Ii (147), testicans 1 (148) and 3 (149), and nidogens/entactins 1 and $2(138,150)$. Besides human thyropins, also equistatin from the beadlet anemone Actinia equina (151), saxiphilin from the bullfrog Rana catesbiana (152), and the chum salmon (Oncorhynchus keta) egg peptidase inhibitor (150) were described as inhibitors of papain and cathepsins $\mathrm{B}$ and $\mathrm{L}$, while equistatin can also inhibit aspartic cathepsin D (153).

The p41 fragment of the invariant chain (Ii) is expressed in two splicing forms, p31 and p41, which differ in the presence of the additional fragment of 64 amino acids in p41 that includes the thyroglobulin type-1 domain (147). The p41 fragment inhibits cathepsins $\mathrm{L}$ and $\mathrm{H}$ as well as papain and cruzipain $(147,154)$. It also plays an important role in antigen presentation, as will be discussed later.

Testicans are extracellular chondroitin/heparan sulfate proteoglycans that were first identified in seminal plasma (155). Three homologues have been found in humans, which share $40-50 \%$ homology and are mostly expressed in the central nervous system, named testicans 1, 2, and 3 (149). Their multidomain structure includes several domains that indicate that they may act as inhibitors. They possess three domains: 1) a domain that inhibits membrane-type 1 matrix metalloproteinase (MT-MMP) activation of MMP-2, 2) a Kazal-like domain present in serine peptidase inhibitors, and 3) the thyroglobulin type-1 domain [summarized in (148)]. Testican 1 is a competitive inhibitor of CatL at acidic (5.5) and neutral (7.2) $\mathrm{pH}$. Protein-protein interactions are needed through which testican 1 not only inhibits CatL but also enhances its stability at neutral $\mathrm{pH}$; the enzyme's activity is thus prolonged at the price of reduced proteolytic activity. Inhibiting MTbuffer1-MMP and 
MT4-MMP, which are important for the processing of MMP2, testicans 1 and 3, and the splicing variant of testican 3, N-Tes (which lacks the thyroglobulin domain), prevents MMP2 activation (149). Testican 2 has not been shown to inhibit cathepsins.

The nidogens/entactins 1 and 2 are ubiquitous components of basement membranes and essential for morphogenesis before and around birth $(156,157)$. Mouse entactin does not show any inhibitory activity toward papain (150). Human thyroglobulin domain 1 of nidogen 1 showed inhibitory activity toward cathepsins L and B with 100-fold molar excess over the enzyme ratio (138).

\section{Serpins}

Serpins, typical inhibitors of serine peptidases, can also inhibit cysteine peptidases through cross-class-specific inhibition (158). Cross-class-specific intracellular serpins were found to inhibit papain-like, lysosomal cysteine cathepsins, such as cathepsins B, V, L, K, and H (158). For example, serine peptidase inhibitor 2A (Spi2A or Serpina3g) inhibits the serine peptidase cathepsin $\mathrm{G}$ but also papain-like, lysosomal cysteine cathepsins such as cathepsins B, V, L, K, and H (159). This crossclass specificity of Spi2A for cysteine cathepsins is also a property of another mouse serpin, SQN-5 (Serpinb3a) (160). Similarly, human squamous cell carcinoma antigen-1 is a potent inhibitor of the cathepsins K, L, and S (161). The serpin hurpin specifically inhibits only CatL in human keratinocytes (162). The mechanism of inhibition of cysteine peptidases involves cleavage of the intracellular serpin through a stable covalent $(158,160)$ or non-covalent $(159,163)$ complex. Intracellular serpins are involved in an inhibitory pathway that regulates a powerful array of lysosomal cysteine proteinases that trigger cell death. As such, there is an emerging view that these serpins are important regulators of cell survival.

\section{REGULATION OF IMMUNE CELL FUNCTIONS BY CYSTEINE CATHEPSINS AND THEIR INHIBITORS}

Immune cell functions are tightly regulated by cathepsins and their endogenous inhibitors. The ratio of both is of extreme importance for normal physiological performance of the immune system $(99,164)$. The most studied processes are antigen processing and the presentation of processed fragments in APCs, the cytotoxicity of CTLs and NK cells, and the protection of the host from invading pathogens (165). As cathepsins perform diverse actions in different cells, we will review their involvement by focusing on cysteine cathepsins.

\section{Antigen Presentation}

DCs are professional APCs that, in their immature form, detect, engulf, and process pathogens. When activated, they lose their ability of capturing and processing and instead migrate to the secondary lymphoid organs in which they present antigens on their surface to prime B and T lymphocytes. As such, DCs connect the innate and adaptive immune responses $(166,167)$.
In DCs, CatS is the major cysteine cathepsin involved in processing and presenting antigens (168) and its activity increases during DC maturation (Figure 2). This is not due to increased CatS expression but to the changes in the expression and localization of its inhibitor, cystatin C. At the same time, step-wise Ii processing also increases (164); this prevents the targeting of MHC class II molecules to lysosomes in which they would degrade. CatS plays a similar role in other BM-derived APCs, while in cortical thymic epithelial cells, CatL was found to be the preferred cysteine cathepsin that is also regulated by cystatin C (101). Other cathepsins, cysteine as well as others (B, $\mathrm{D}, \mathrm{E}$, and legumain, also known as asparaginyl endopeptidase) also participate but are not essential in antigen processing (13).

The expression of cystatin $\mathrm{C}$ in immune cells depends on their differentiation status and maturity (169). High cystatin C levels are found in lysosomes of immature DCs; however, cystatin C levels significantly decrease during DC maturation $(170,171)$. Cystatin C expression varies between different DC subsets, and thus it may not be necessary nor sufficient to control MHC class II molecule expression and antigen presentation. Furthermore, in cystatin C knockout mice, mature DCs displayed no defect in MHC class II molecule surface expression (172). However, cystatin $\mathrm{C}$ can influence the expression of surface MHC class II molecules through decreased expression of chaperone H2-DM (173) and thus inhibits CD4+ T-cell proliferation. It can also stimulate DCs to secrete more of the immune suppressive cytokines IL-10 and transforming growth factor $\beta$ (TGF $\beta$ ) and less of the pro-inflammatory cytokine TNF $\alpha$ (174). It also inhibits antigen presentation by MHC class I molecules that leads to compromised activation of CD8+ T cells (174). To sum up, the mechanisms underlying cystatin $\mathrm{C}$ action, including its role in antigen presentation, are far from understood. Infection with Ectromelia virus in murine conventional DCs, leads to downregulation of cathepsins $\mathrm{B}, \mathrm{L}$, and $\mathrm{S}$ and cystatins $\mathrm{B}$ and $\mathrm{C}$, diminishing their ability to process antigen, that results in induction of insufficient adaptive immune response (175). Additionally, cystatin D (176) and cystatin F (177) seem to play a role in antigen presentation.

\section{Cytotoxicity of CTLs and NK Cells}

CTLs and NK cells are major effector cells of the immune system, killing their targets through the perforin/granzyme pathway. After recognizing a cell that has been infected by a virus or transformed, they release the content of their cytotoxic granules into the lytic synapse between the killer cell and target cell. Cytotoxic granules consist of a plethora of proteins, including perforin, serine peptidase granzymes, and cathepsins $\mathrm{C}, \mathrm{H}$, and $\mathrm{L}$ (178). Perforin is a pore-forming protein that enables the entry of granzymes A and B into the target cell. Granzymes A and B then trigger apoptosis through different signaling pathways, both with or without activation of caspases $(179,180)$. Perforin is activated proteolytically by CatL. In CatL-deficient NK cells from mice, a small amount of perforin is still processed (181). CatC activates both granzymes by proteolytic cleavage (182), while in the absence of CatC, CatH takes over by activating granzyme $\mathrm{B}$. Still, when lacking both cathepsins, mice still retain low activity of granzyme B, indicating the involvement of yet another 
peptidase (183) (Figure 2). Legumain may also play a role in NK cells, as they display lower cytotoxic activity in legumain-null mice (184). Cysteine cathepsins from cytotoxic granules as well as the tight regulation of their activities are thus indispensable for the killing functions of CTLs and NK cells. Cystatin F is the most important candidate for such regulation.

Cystatin $\mathrm{F}$ is expressed as an inactive dimer and first needs to be converted to its monomeric form (185). As a monomer, it is a potent inhibitor of cathepsins F, K, L, and V and to a lesser extent of cathepsins $\mathrm{H}$ and $\mathrm{S}$ (185). However, if the monomers are further processed on the $\mathrm{N}$-termini, truncated cystatin $\mathrm{F}$ becomes a strong inhibitor of CatC (186). Another distinct feature of cystatin F is that it can also function in trans. After secretion, it is taken up by surrounding cells (187) in which it is then activated within endolysosomal vesicles. Here, cystatin $\mathrm{F}$ inactivates cathepsins $\mathrm{C}$ and $\mathrm{H}$, which leads to reduced cytotoxicity of these cells $(180,188)$. Furthermore, cathepsins B and S (189) have been implicated in the activation of invariant NKTs, capable of recognizing lipids in an antigen-specific manner and rapidly secreting high amounts of cytokines upon antigenic stimulation.

\section{Protection of the Host From Invading Pathogens}

Eosinophils are effector cells of the immune system that are imperative for the defense against nematodes and other parasites. They also participate in the inflammatory response of allergic reactions (190). Eosinophils have abundant intracellular granules containing major basic proteins, other highly toxic proteins, and cathepsins S, B, X, C, and L, which process major basic proteins and other proteins during granule biogenesis. Cystatin $\mathrm{F}$ was reported to be a survival factor for eosinophils, especially for eosinophils with high granule content. It regulates the activities of cysteine peptidases, which are critical for normal granule biogenesis. Furthermore, cystatin $\mathrm{F}$ also protects eosinophils from being harmed by their toxic proteins and is thus essential for eosinophil viability (191). Cystatin SN is another endogenous inhibitor that is important for eosinophil immunity. It is involved in the activation and recruitment of eosinophils during eosinophilic inflammation. Cystatin SN derived from epithelial cells induces IL-5 production that promotes the synthesis of granule proteins, and cystatin SN expression is controlled by several cytokines (192).

Neutrophils are effectors of the rapid innate host defense response against bacteria and fungi. They can promptly migrate to sites of inflammation, engulf foreign bodies, and produce several microbicidal substances such as superoxide [summarized from (193)]. CatC activates certain serine peptidases that are found in mature neutrophils such as cathepsin G, proteinase 3, and neutrophil elastase (194). CatS activates CatC in a stepwise manner in neutrophilic precursor cells. Neutrophils are also the source of CatC (195). Conversely, cystatin C plays a role in neutrophil migration through modulating chemotaxis and regulating the phagocytic function of polymorphonuclear neutrophils (196).

Monocytes and macrophages actively participate in the innate immune response. They recruit and activate other immune cells by secreting a wide range of pro-inflammatory (M2-polarized macrophages; IL-12, TNF $\alpha$ ) and immunomodulatory (M1polarized macrophages; IL-4, IL-10) cytokines and chemokines [summarized from (197)]. During differentiation from monocytes to macrophages, the intracellular proteolytic profile significantly changes. Even though the expression levels of cathepsins L, S, and C, and legumain decrease, their activities increase in macrophages because the precursor-to-active form ratio stays the same. This is due to the absence of cystatin $\mathrm{F}$ that is mainly present in monocytes but not in macrophages. One exception is $\mathrm{CatH}$ with unchanged activity (198). The expression of cystatin $\mathrm{F}$ is regulated by transcription factor $\mathrm{C} / \mathrm{EBP} \alpha$, whose expression declines during monocyte differentiation (78). C/ EBP $\alpha$ binds to the promoter region of the cystatin $\mathrm{F}$ gene, and this binding decreases after differentiation (198).

Cystatin C is expressed constitutively in monocytes/ macrophages (79) and influences the phenotype of monocytes (199). During bone formation, it reduces osteoclastic activity by inhibiting cathepsins and is as such required for macrophagemediated regulation of bone cells (199). Next, the expression of cystatin $\mathrm{C}$ increases during the differentiation of monocytes to immature DCs (170). In microglia (resident macrophages of the nervous system), cystatin $\mathrm{C}$ modifies migration, possibly by neutralizing ECM remodeling cathepsins (81). During the differentiation of monocytes to macrophages, stefin B mRNA increases (200). Stefin B was proposed to play a role in the innate immune response to bacterial infection (201).

In general, one or more cathepsins and their inhibitors are involved in every step of the immune response, from pathogen entrance to the final immune effect. Cathepsins activate TLRs. Cathepsins B, L, S, and F were shown to cleave TLR-7 and -9 (202). They also activate or inhibit different cytokines and are themselves regulated by cytokines $(203,204)$. CatB is needed for the processing and production of TNF $\alpha$ in response to bacterial lipopolysaccharide (LPS). It obstructs the trafficking of TNF $\alpha$ containing vesicles to the plasma membrane (205). The expression of cystatin $\mathrm{C}$ increases after LPS-induced stimulation of monocytes (201). CatB reduces the production of the proinflammatory cytokines IL-1b and TNF $\alpha$ by decreasing ERK1/ 2 phosphorylation that leads to down-regulated transcription of certain cytokines (199). The same study also showed that cystatin C induces the release of the proinflammatory cytokines IL-6 and IL-8 in non-pathogenically activated monocytes. Cystatin C in DCs suppresses DC-induced differentiation of $\mathrm{T}$ cells that have more anti-inflammatory potential (174). Cystatin C is possibly also involved in the regulation of complement activation because it binds to complement factor C4 (206).

CatX regulates the migration, proliferation, maturation, phagocytosis, signal transduction, and adhesion of DCs, monocytes, and macrophages. As a carboxymonopeptidase, it acts through proteolytic cleavage of the C-terminus of integrin receptors or through its tripeptide motif Arg-Gly-Asp (RGD) $(44,207)$. Thus, it can indirectly also affect the function of cytotoxic cells. Although cystatin F cannot inhibit CatX, it affects CatX $(138,185)$ by inhibiting CatL, which is necessary for the activation of CatX. In DCs, cystatin F possibly regulates 
the activity of CatL, thus controlling the processing of pro-CatX, which promotes cell adhesion (208).

\section{THE ROLE OF CATHEPSINS AND THEIR INHIBITORS IN INDUCING TOLERANCE AND ANERGY IN IMMUNE CELLS}

Cathepsins are also involved in the induction of apoptosis in immune cells as a mechanism to regulate inappropriate immune responses. In a model of Ag-specific unresponsiveness, i.e., high dose tolerance, the incubation of $\mathrm{T}$ cells with increasing antithymocyte globulin concentrations in vitro reduced lymphocyte proliferative responses. This was associated with a rapid increase in the percentage of apoptotic cells as a consequence of cytosolic CatB activity (209). Similarly, the exposure of peripheral blood monocytes to increasing mitogen concentrations reduced the proliferative response and release of $\mathrm{CatB}$ and $\mathrm{CatL}$ into the cytosol as a consequence of LMP (210). CatV was implicated in promotion of the maturation of thymocytes, including those with an autoimmune potential and increased expression of CatV has been found in thymi of Myasthenia Gravis patients (103). Finally, the increased expression of CatS involved in MHC II-dependent antigen presentation in DCs was shown to lead to improper antigen presentation, associated with the development of autoimmunity (211) (Figure 1).

In germinal centers, B lymphocytes with high-affinity B-cell receptors are selected and B-cells with unwanted specificities are eliminated. Apoptotic death in germinal center B lymphocytes can be blocked not only by inhibition of caspase- 8 or caspase- 3 but also by inhibition of cathepsins (212). This antigendependent germinal center $B$ cell death was shown to be a consequence of LMP and release of cathepsins B and L into the cytosol, whereas the interaction with follicular DCs and CD40 ligation was shown to rescue B cells from LMP and apoptosis (213).

NK cells lose the ability to mediate cytotoxicity and downregulate CD16 receptor expression upon interaction with cancer stem cells (CSCs)/undifferentiated tumors or through crosslinking of CD16 receptors by antibodies, while maintaining secretion of IFN- $\gamma$ and TNF- $\alpha$. This functional state of NK cells, termed "split anergy" is characterized by a selective loss or decrease in cytotoxicity and an increase in cytokine and chemokine production (214). An in vitro study showed that this loss of NK cell cytotoxicity is a consequence of decreased activity of the key granzyme-activating cathepsins $\mathrm{C}$ and $\mathrm{H}$ and increased concentration of their endogenous inhibitor, cystatin $\mathrm{F}$ (215). Similarly, the induction of functional anergy in CD8+ T lymphocytes using ionomycin or TGF $\beta$ decreased the activity of cathepsins $\mathrm{C}$ and $\mathrm{H}$ and increased the concentration of cystatin $\mathrm{F}$ (180). Cystatin F is only partially targeted to endo-lysosomes upon its synthesis, and can also be secreted and taken up by surrounding cells (188). The uptake of exogenous cystatin F was also shown to reduce the cytotoxicity of NK cells and T cells (188, 216). Furthermore, proinflammatory cytokines, such as IFN- $\gamma$ and TNF- $\alpha$, increase cathepsin S and B activities in DCs (217,
218), whereas IL-10, which induces tolerogenic DCs and consequently $\mathrm{T}$ lymphocyte anergy (219), prevents the upregulation of cathepsin S and B activities in DCs (220). The changes in CatS activity in activated DCs could be, at least in part, attributed to changes in endo-lysosomal levels of its endogenous inhibitor, cystatin C (164).

\section{THE ROLE OF CATHEPSINS AND THEIR INHIBITORS IN IMMUNOSENESCENCE}

Age-related declines in the immune system, known as immunosenescence, result in increased susceptibility to infectious diseases, tumors, and autoimmune diseases as well as impaired responses to vaccination in older individuals. The deterioration of the immune response during aging can at least partially be attributed to changes in the major cellular proteolytic mechanisms mediated by the lysosome (221). During senescence, lysosomes undergo various changes that decrease their degradative capacity. Age-associated increases in the size and numbers of lysosomes (222) as well as in the enhanced fragility and increased LMP in response to various stimuli (223) have been well documented.

CatK serum levels were shown to decrease with age (224). Furthermore, aging affects the composition of the ECM, and the aging-associated changes of collagen fibers were suggested to influence the collagenolytic activity of CatK. The accumulation of advanced glycation end-products and mineralization were all shown to reduce CatK collagenolytic activity, while the removal of GAGs completely blocked this activity (225). The amount of chondroitin sulfate, a major subtype of GAGs in bone, also decreases with ageing (226).

Whereas tightly regulated, short-term, acute inflammation is a normal defense mechanism that acts against harmful agents, dysregulation of the immune response leads to chronic systemic inflammatory states. Age-associated chronic inflammation is characterized by unresolved and uncontrolled inflammation that exacerbates the aging process and age-related chronic diseases. Among the dysregulated proinflammatory cytokines and chemokines, elevated expression and secretion of cathepsins is an important culprit underlying the development and progression of cancer, autoimmunity, atherosclerosis, neurodegeneration, and osteoporosis $(14,32,227)$ with age. For example, a rich source of cathepsins in the brain are activated microglia (228). They can comprise up to $20 \%$ of the total glial cell population. Microglia-secreted cathepsins, such as CatS and CatX, were found to be upregulated in mouse microglia with aging $(229,230)$. Activated microglia were suggested to be involved in neuroinflammation that accompanies numerous neurodegenerative disorders, including Alzheimer's disease.

The age-associated decline of T-cell function is complex and occurs at multiple levels. Whereas maintaining memory cells is of utmost importance for subsequent encounters with antigens, senescent CD8+ T cells accumulate over time and can constitute $>50 \%$ of the peripheral blood CD8+ T-cell pool in the elderly due to their resistance to apoptosis (231). The accumulation of senescent CD8+ $\mathrm{T}$ cells influences the quality of the memory 
T-cell pool, impairs the capacity to respond to vaccination, and is highly associated with age-related diseases (231). A recent study showed that Serpina3g (that encodes Spi2A and is necessary for counteracting the pro-apoptotic effects of CatB and the maintenance of long-term memory CD8+ T cells) expression was increased in both old CD8+ central memory (TCM) and effector memory (TEM) cells, supporting the long-term survival of CD8 T memory cells (232). Furthermore, a cohort of healthy elderly volunteers exhibited no differences in CatB activity in their granulocytes, monocytes, or lymphocytes but exhibited increased CatC (DPP I) activity in their lymphocytes, compared with young controls (233). This is in line with data suggesting that a high proportion of cytotoxic cells, as well as proper cytotoxic functions during senescence, are determining factors for healthy ageing (234).

\section{CATHEPSINS AND THEIR INHIBITORS AS CHEMOTHERAPEUTIC TARGETS FOR MODULATING IMMUNE CELL FUNCTIONS}

Pharmacological inhibition or targeted disruption of cathepsins has been widely studied in the context of cancer and pathological conditions involving bone and cartilage. With few exceptions, the potential of cathepsins in regulating and regenerating immune cell function is only beginning to be explored (Table 2).

Due to its central role in ECM degradation and bone remodeling, CatK is currently considered one of the most promising targets for the treatment of osteoporosis (235). Increased CatK levels were found in synovial fluids and the lining tissue inside arthritic joints from patients with rheumatoid arthritis, implicating CatK in the development and/or progression of this disease (236). Pharmacological inhibition or targeted disruption of CatK resulted in defective TLR9 signaling in DCs in response to unmethylated CpG DNA, which in turn led to an attenuated induction of Th17 cells. These data suggest that CatK may serve as a valid therapeutic target in autoimmune diseases (115). Specific inhibitor of CatS (Clik60) in vitro markedly impaired presentation of an organ-specific autoantigen, $120-\mathrm{kDa}$ alpha-fodrin, by interfering with MHC class II-peptide. Treatment with CatS inhibitor in vivo was effective in preventing the development of autoimmune lesions in the salivary and lacrimal glands of the Sjögren syndrome model mice (237).

In vitro studies using targeted disruption of cathepsins identified cathepsins $\mathrm{B}, \mathrm{C}, \mathrm{L}$, and $\mathrm{S}$ as potential modulators of immune cell activity in diseases such as cancer. Whereas CatS inhibition enhances immunosuppressive activity of Tregs under normal conditions, transfer of CatS inhibitor-treated Tregs into bladder carcinoma MB49 model mice led to reduction in number of splenic and tumor Tregs, and reduction of tumor and splenic cell proliferation compared to control animals (238). The tumor microenvironment is particularly conducive to the development of M2 macrophages and myeloid-derived suppressor cells, which potently suppress the anti-cancer immune response. In comparison to their anti-tumor counterparts, these cells significantly upregulate the expression and activity of cysteine cathepsins $(75,239)$. Blocking these cysteine cathepsins could inhibit their immunosuppressive functions, subsequently alleviating the tumor burden. Experiments in vivo support this rationale. Genetic ablation of CatB successfully prevented the accumulation of myeloid-derived suppressor cells and attenuated polyposis in a mouse $\mathrm{APC}^{\Delta 468}$ model (240). GB111- $\mathrm{NH}_{2}$, a broad-spectrum inhibitor of cathepsins B, L, and S, which was applied to $4 \mathrm{~T} 1$ tumor-bearing mice, induced tumor regression as a result of macrophage apoptosis. The inhibitor was also used to study the effects of cathepsin inhibition on macrophage metabolism and phenotype. Due to derailed autophagy and lysosomal signaling, cathepsin inhibition triggered cellular stress and apoptosis of murine macrophages (241) and promoted metabolic changes, which induced the M1 shift in human macrophages, including enhanced glycolysis and synthesis of pro-inflammatory mediators (242).

A specific inhibitor of CatB (CA074) was shown to modulate the immune responses of BALB/c mice infected with Leishmania major (243-245). This inhibitor suppressed the Th2 response but augmented the Th1 response, suggesting that CatB functions as an antigen-processing peptidase and preferentially activates the Th2 response. In contrast, treating L. major-infected BALB/c mice with CLIK148, a specific inhibitor of CatL, enhances the development of the disease-promoting Th 2 response (246) (Table 2).

TABLE 2 | The effects of cysteine cathepsin activity modulation on immune cell subset differentiation.

\section{T lymphocytes}

Th1 Treatment of Leishmania major -infected BALB/c mice with a specific inhibitor of Cathepsin B (CA074) augmented the Th1 response (232).

Th2 Treatment of Leishmania major -infected BALB/c mice with a specific inhibitor of Cathepsin L (CLIK148), enhances the development of Th2 response (235).

Th17 Theatment with specific Cathepsin L inhibitor inhibits differentiation of Th17 T cells (106).

Cathepsin K inhibition decreased Th17 cell induction in response to unmethylated CpG DNA thorough defective TLR 9 signaling in DCs (108).

Cathepsin S-induced IL-6 production by splenic DCs promotes Th17 differentiation, in response to systemic exposure to LPS derived from Porphyromonas gingivalis (PgLPS) in mice (110).

Tregs Cathepsin S inhibition under influence of tumor cells inhibits Treg immunosupressive activity (226).

\section{Macrophages}

M1 Increased Cathepsin C activity promotes macrophage M1 polarization trough FAK-induced p38MAPK/NF- $\mathrm{KB}$ signaling pathway (117).

M1 Inhibition of cathepsins B, L, and S with GB111-NH2, leads to polarization shift from M2- to M1 macrophages (231).

M2 Cathepsin S knockout inhibited M2 macrophage polarization during tumor development (116).

TLR9, Toll-like receptor 9; FAK, Focal Adhesion Kinase; MAPK, mitogen-activated protein kinase; NF-kB, Nuclear factor-kB; DCs, dendritic cells; Tregs, regulatory T cells. 
Furthermore, several reports demonstrated that the selective CatB inhibitor CA-074Me can reduce LMP and cell death in several in vivo models, including a mouse model of metastatic cancer (247), a mouse model of Kawasaki disease (248), and during mammary gland involution, where it delays the regression of the gland after weaning (249). The involvement of CatB in the lysosomal cell death pathway and activation of the NLRP3 inflammasome has attracted much attention (250). Recently it was shown that in mouse BMDMs treated with different types of NLRP3 activators (ATP, nigericin or crystals) CatB is necessary for caspase- 1 activation, IL- $1 \beta$ production and ASC speck formation (251). CatB presence in the cytoplasm, was shown to be necessary for its interaction with NLRP3 (251). Moreover, CA-074Me was also described to inhibit monosodium urate (MSU)-induced IL-1 $\alpha$ and IL-6 production (252). Another cysteine peptidase inhibitor, E64d, reduced srp-6 null Caenorhabditis elegans-induced LMP (253).

In addition to cathepsins, their endogenous inhibitors are potential targets for pharmacological inhibition. Silencing of naturally occurring cathepsin inhibitors, such as cystatins and serpins, which attenuate the cytosolic activity of cathepsins and hence LMP-driven apoptosis, may induce apoptosis and consequently be therapeutically useful in autoimmune lymphocyte populations, pathogen-infected cells, and tumor cells. In addition, recent findings $(188,216)$ suggest that decreasing the intracellular uptake or activation of cystatin $\mathrm{F}$ could increase the efficacy of target cell killing by cytotoxic cells (NK cells and CD8+ T cells), thus improving the antitumor immune response.

\section{REFERENCES}

1. Muller S, Dennemarker J, Reinheckel T. Specific Functions of Lysosomal Proteases in Endocytic and Autophagic Pathways. Biochim Biophys Acta (2012) 1824(1):34-43. doi: 10.1016/j.bbapap.2011.07.003

2. Fonović M, Turk B. Cysteine Cathepsins and Extracellular Matrix Degradation. Biochim Biophys Acta (2014) 1840(8):2560-70. doi: 10.1016/j.bbagen.2014.03.017

3. Rossi A, Deveraux Q, Turk B, Sali A. Comprehensive Search for Cysteine Cathepsins in the Human Genome. Biol Chem (2004) 385(5):363-72. doi: 10.1515/BC. 2004.040

4. Zavasnik-Bergant T, Turk B. Cysteine Proteases: Destruction Ability Versus Immunomodulation Capacity in Immune Cells. Biol Chem (2007) 388 (11):1141-9. doi: 10.1515/BC.2007.144

5. Hou WS, Li Z, Gordon RE, Chan K, Klein MJ, Levy R, et al. Cathepsin K Is a Critical Protease in Synovial Fibroblast-Mediated Collagen Degradation. Am J Pathol (2001) 159(6):2167-77. doi: 10.1016/S0002-9440(10)63068-4

6. Kopitar-Jerala N, Bevec T, Barlic-Maganja D, Gubensek F, Turk V. AntiCathepsin L Monoclonal Antibodies That Distinguish Cathepsin L From Cathepsin V. Biol Chem (2001) 382(5):867-70. doi: 10.1515/bchm.2001.382.5.867

7. Wang Y, Baron RM, Zhu G, Joo M, Christman JW, Silverman ES, et al. PU.1 Regulates Cathepsin S Expression in Professional APCs. J Immunol (2006) 176 (1):275 LP-83. doi: 10.4049/jimmunol.176.1.275

8. Kos J, Sekirnik A, Premzl A, Zavasnik Bergant V, Langerholc T, Repnik UK, et al. Carboxypeptidases Cathepsins $\{\mathrm{X}\}$ and $\{\mathrm{B}\}$ Display Distinct Protein Profile in Human Cells and Tissues. Exp Cell Res (2005) 306(1):103-13. doi: 10.1016/j.yexcr.2004.12.006

9. Pišlar A, Božić B, Zidar N, Kos J. Inhibition of Cathepsin X Reduces the Strength of Microglial-Mediated Neuroinflammation. Neuropharmacology (2017) 114:88-100. doi: 10.1016/j.neuropharm.2016.11.019

10. Stoeckle C, Gouttefangeas CC, Hammer M, Weber E, Melms A, Tolosa E. Cathepsin W Expressed Exclusively in CD8+ T Cells and NK Cells, Is Secreted

\section{CONCLUSIONS}

Cysteine cathepsins play important roles in maintaining immune cell functions and homeostasis in the immune system. Due to their important roles in pathological conditions such as chronic inflammation, autoimmune disorders, and cancer, cathepsins and their inhibitors represent attractive therapeutic targets. Their emerging roles in the regulation of extra-lysosomal and extracellular proteolysis reveal new targets that can be pharmacologically modulated without disrupting their lysosomal function. To that end, future investigations are needed to study the molecular mechanism(s) controlling lysosomal membrane stability under physiological and pathological conditions as well as to develop new strategies to regulate the activity of cathepsins and their endogenous inhibitors.

\section{AUTHOR CONTRIBUTIONS}

MPN, UP, and TJ, original draft preparation. MPN, draft editing. $\mathrm{JK}$, review and editing. MPN, visualization. MPN and JK, funding acquisition. All authors contributed to the article and approved the submitted version.

\section{FUNDING}

This research was funded by Research Agency of the Republic of Slovenia, grant numbers J3-2516 to MPN and P4-0127 to JK.

During Target Cell Killing But Is Not Essential for Cytotoxicity in Human CTLs. Exp Hematol (2009) 37(2):266-75. doi: 10.1016/j.exphem.2008.10.011

11. López-Otín C, Bond JS. Proteases: Multifunctional Enzymes in Life and Disease. J Biol Chem (2008) 283(45):30433-7. doi: 10.1074/jbc.R800035200

12. Neurath H. Proteolytic Enzymes, Past and Future. Proc Natl Acad Sci U S A (1999) 96(20):10962-3. doi: 10.1073/pnas.96.20.10962

13. Conus S, Simon HU. Cathepsins and Their Involvement in Immune Responses. Swiss Med Wkly (2010) 140:w13042. doi: 10.4414/smw.2010.13042

14. Jakos T, Pislar A, Jewett A, Kos J. Cysteine Cathepsins in Tumor-Associated Immune Cells. Front Immunol (2019) 10:2037-. doi: 10.3389/fimmu.2019.02037

15. Frankel MAX, Maimin R. Natural Activation of Papain. Nature (1937) 140 (3554):1015-. doi: 10.1038/1401015b0

16. Rawlings ND, Waller M, Barrett AJ, Bateman A. MEROPS: The Database of Proteolytic Enzymes, Their Substrates and Inhibitors. Nucleic Acids Res (2013) 42(D1):D503-D9. doi: 10.1093/nar/gkt953

17. Turk V, Stoka V, Vasiljeva O, Renko M, Sun T, Turk B, et al. Cysteine Cathepsins: \{From\} Structure, Function and Regulation to New Frontiers. Biochim Biophys Acta (BBA) - Proteins Proteomics (2012) 1824(1):68-88. doi: 10.1016/j.bbapap.2011.10.002

18. Vasiljeva O, Reinheckel T, Peters C, Turk D, Turk V, Turk B. Emerging Roles of Cysteine Cathepsins in Disease and Their Potential as Drug Targets. Curr Pharm Des (2007) 13(4):387-403. doi: 10.2174/138161207780162962

19. Loser R, Pietzsch J. Cysteine Cathepsins: Their Role in Tumor Progression and Recent Trends in the Development of Imaging Probes. Front Chem (2015) 3:37-. doi: 10.3389/fchem.2015.00037

20. Braulke T, Bonifacino JS. Sorting of Lysosomal Proteins. Biochim Et Biophys Acta (BBA) - Mol Cell Res (2009) 1793(4):605-14. doi: 10.1016/ j.bbamcr.2008.10.016

21. Staudt C, Puissant E, Boonen M. Subcellular Trafficking of Mammalian Lysosomal Proteins: An Extended View. Int J Mol Sci (2016) 18(1):47-. doi: 10.3390/ijms18010047 
22. Wiederanders B, Kaulmann G, Schilling K. Functions of Propeptide Parts in Cysteine Proteases. Curr Protein Pept Sci (2003) 4(5):309-26. doi: 10.2174/ 1389203033487081

23. Barrett AJ, Kirschke H. Cathepsin B, Cathepsin H, Cathepsin L. Methods Enzymol (1981) 80 Pt C:535-61. doi: 10.1016/S0076-6879(81)80043-2

24. Turk D, Guncar G, Podobnik M, Turk B. Revised Definition of Substrate Binding Sites of Papain-Like Cysteine Proteases. Biol Chem (1998) 379 (2):137-47. doi: 10.1515/bchm.1998.379.2.137

25. Turk D, Guncar G. Lysosomal Cysteine Proteases (Cathepsins): Promising Drug Targets. Acta Crystallogr D Biol Crystallogr (2003) 59(Pt 2):203-13. doi: $10.1107 / \mathrm{S} 0907444902021479$

26. Fengler A, Brandt W. Three-Dimensional Structures of the Cysteine Proteases Cathepsins K and S Deduced by Knowledge-Based Modelling and Active Site Characteristics. Protein Eng (1998) 11(11):1007-13. doi: 10.1093/protein/ 11.11.1007

27. Vidak E, Javorsek U, Vizovisek M, Turk B. Cysteine Cathepsins and Their Extracellular Roles: Shaping the Microenvironment. Cells (2019) 8(3):264-88. doi: 10.3390/cells 8030264

28. Jevnikar Z, Obermajer N, Doljak B, Turk S, Gobec S, Svajger U, et al. Cathepsin X Cleavage of the Beta2 Integrin Regulates Talin-Binding and LFA-1 Affinity in T Cells. J Leukoc Biol (2011) 90(1):99-109. doi: 10.1189/ jlb.1110622

29. Jevnikar Z, Obermajer N, Pečar-Fonović U, Karaoglanovic-Carmona A, Kos J. Cathepsin X Cleaves the $\beta 2$ Cytoplasmic Tail of LFA-1 Inducing the Intermediate Affinity Form of LFA-1 and $\alpha$-Actinin-1 Binding. Eur $J$ Immunol (2009) 39(11):3217-27. doi: 10.1002/eji.200939562

30. Pečar Fonović U, Jevnikar Z, Rojnik M, Doljak B, Fonović M, Jamnik P, et al. Profilin 1 as a Target for Cathepsin X Activity in Tumor Cells. PloS One (2013) 8(1):e53918. doi: 10.1371/journal.pone.0053918

31. Jevnikar Z, Rojnik M, Jamnik P, Doljak B, Fonovic UP, Kos J. Cathepsin H Mediates the Processing of Talin and Regulates Migration of Prostate Cancer Cells. J Biol Chem (2013) 288(4):2201-9. doi: 10.1074/jbc.M112.436394

32. Kramer L, Turk DA, Turk B. The Future of Cysteine Cathepsins in Disease Management. Trends Pharmacol Sci (2017) 38(10):873-98. doi: 10.1016/ j.tips.2017.06.003

33. Salvesen GS. A Lysosomal Protease Enters the Death Scene. J Clin Invest (2001) 107(1):21-2. doi: 10.1172/JCI11829

34. Song J, Xu P, Xiang H, Su Z, Storer AC, Ni F. The Active-Site Residue Cys-29 Is Responsible for the Neutral-pH Inactivation and the Refolding Barrier of Human Cathepsin B. FEBS Lett (2000) 475(3):157-62. doi: 10.1016/S00145793(00)01644-6

35. Vasiljeva O, Dolinar M, Pungercar JR, Turk V, Turk B. Recombinant Human Procathepsin S Is Capable of Autocatalytic Processing at Neutral $\mathrm{pH}$ in the Presence of Glycosaminoglycans. FEBS Lett (2005) 579(5):1285-90. doi: 10.1016/j.febslet.2004.12.093

36. Turk B, Dolenc I, Turk V, Bieth JG. Kinetics of the pH-Induced Inactivation of Human Cathepsin L. Biochemistry (1993) 32(1):375-80. doi: 10.1021/ bi00052a046

37. Novinec M, Lenarcic B, Turk B. Cysteine Cathepsin Activity Regulation by Glycosaminoglycans. BioMed Res Int (2014) 2014:1-9. doi: 10.1155/2014/309718

38. Nilsson C, Johansson U, Johansson A-C, Kågedal K, Öllinger K. Cytosolic Acidification and Lysosomal Alkalinization During TNF- $\alpha$ Induced Apoptosis in U937 Cells. Apoptosis (2006) 11(7):1149. doi: 10.1007/s10495006-7108-5

39. de Castro MAG, Bunt G, Wouters FS. Cathepsin B Launches an Apoptotic Exit Effort Upon Cell Death-Associated Disruption of Lysosomes. Cell Death Discov (2016) 2(1):16012. doi: 10.1038/cddiscovery.2016.12

40. Holt OJ, Gallo F, Griffiths GM. Regulating Secretory Lysosomes. J Biochem (2006) 140(1):7-12. doi: $10.1093 / \mathrm{jb} / \mathrm{mvj} 126$

41. Stinchcombe JC, Griffiths GM. Regulated Secretion From Hemopoietic Cells. J Cell Biol (1999) 147(1):1-6. doi: 10.1083/jcb.147.1.1

42. Dell'Angelica EC, Mullins C, Caplan S, Bonifacino JS. Lysosome-Related Organelles. FASEB J (2000) 14(10):1265-78. doi: 10.1096/fasebj.14.10.1265

43. Blott EJ, Griffiths GM. Secretory Lysosomes. Nat Rev Mol Cell Biol (2002) 3 (2):122-31. doi: 10.1038/nrm732

44. Jevnikar Z, Obermajer N, Bogyo M, Kos J. The Role of Cathepsin X in the Migration and Invasiveness of T Lymphocytes. J Cell Sci (2008) 121(16):265261. doi: $10.1242 /$ jcs. 023721
45. Weiss RE, Liu BC, Ahlering T, Dubeau L, Droller MJ. Mechanisms of Human Bladder Tumor Invasion: Role of Protease Cathepsin B. J Urol (1990) 144 (3):798-804. doi: 10.1016/S0022-5347(17)39595-2

46. Mai J, Finley RL, Waisman DM, Sloane BF. Human Procathepsin B Interacts With the Annexin II Tetramer on the Surface of Tumor Cells. J Biol Chem (2000) 275(17):12806-12. doi: 10.1074/jbc.275.17.12806

47. Cheng XW, Kuzuya M, Nakamura K, Di Q, Liu Z, Sasaki T, et al. Localization of Cysteine Protease, Cathepsin S, to the Surface of Vascular Smooth Muscle Cells by Association With Integrin Alphanubeta3. Am J Pathol (2006) 168 (2):685-94. doi: 10.2353/ajpath.2006.050295

48. Lechner AM, Assfalg-Machleidt I, Zahler S, Stoeckelhuber M, Machleidt W, Jochum M, et al. RGD-Dependent Binding of Procathepsin X to Integrin Î $\pm \mathrm{V}$ Î 3 Mediates Cell-Adhesive Properties. J Biol Chem (2006) 281(51):39588-97. doi: $10.1074 /$ jbc.M513439200

49. Mostov K, Werb Z. Journey Across the Osteoclast. Science (New York NY) (1997) 276(5310):219-20. doi: 10.1126/science.276.5310.219

50. Soond SM, Kozhevnikova MV, Frolova AS, Savvateeva LV, Plotnikov EY, Townsend PA, et al. Lost or Forgotten: The Nuclear Cathepsin Protein Isoforms in Cancer. Cancer Lett (2019) 462:43-50. doi: 10.1016/j.canlet.2019.07.020

51. Fei Y, Xiong Y, Shen X, Zhao Y, Zhu Y, Wang L, et al. Cathepsin L Promotes Ionizing Radiation-Induced U251 Glioma Cell Migration and Invasion Through Regulating the GSK-3î,/CUX1 Pathway. Cell Signal (2018) 44:6271. doi: 10.1016/j.cellsig.2018.01.012

52. Bach A-S, Derocq D, Laurent-Matha VR, Montcourrier P, Sebti S, Orsetti BA, et al. Nuclear Cathepsin D Enhances TRPS1 Transcriptional Repressor Function to Regulate Cell Cycle Progression and Transformation in Human Breast Cancer Cells. Oncotarget (2015) 6(29):28084-103. doi: 10.18632/oncotarget.4394

53. Wang Y, Niu H, Hu Z, Zhu M, Wang L, Han L, et al. Targeting the Lysosome by an Aminomethylated Riccardin D Triggers DNA Damage Through Cathepsin B-Mediated Degradation of BRCA1. J Cell Mol Med (2019) 23 (3):1798-812. doi: $10.1111 / \mathrm{jcmm} .14077$

54. Kim S, Jin H, Seo H-R, Lee HJ, Lee Y-S. Regulating BRCA1 Protein Stability by Cathepsin S-Mediated Ubiquitin Degradation. Cell Death Differ (2019) 26 (5):812-25. doi: 10.1038/s41418-018-0153-0

55. Grotsky DA, Gonzalez-Suarez I, Novell A, Neumann MA, Yaddanapudi SC, Croke M, et al. BRCA1 Loss Activates Cathepsin L-Mediated Degradation of 53BP1 in Breast Cancer Cells. J Cell Biol (2013) 200(2):187-202. doi: 10.1083/ jcb.201204053

56. Boya P, Andreau K, Poncet D, Zamzami N, Perfettini JL, Metivier D, et al. Lysosomal Membrane Permeabilization Induces Cell Death in a Mitochondrion-Dependent Fashion. J Exp Med (2003) 197(10):1323-34. doi: 10.1084/jem.20021952

57. Boya P, Kroemer G. Lysosomal Membrane Permeabilization in Cell Death. Oncogene (2008) 27(50):6434-51. doi: 10.1038/onc.2008.310

58. Repnik UK, Hafner ÄŚesen MA, Turk B. Lysosomal Membrane Permeabilization in Cell Death: Concepts and Challenges. Mitochondrion (2014) 19:49-57. doi: 10.1016/j.mito.2014.06.006

59. Droga-Mazovec G, Bojic L, Petelin A, Ivanova S, Romih R, Repnik U, et al. Cysteine Cathepsins Trigger Caspase-Dependent Cell Death Through Cleavage of Bid and Antiapoptotic Bcl-2 Homologues. J Biol Chem (2008) 283(27):19140-50. doi: 10.1074/jbc.M802513200

60. Werneburg NW, Guicciardi ME, Bronk SF, Gores GJ. Tumor Necrosis FactorAlpha-Associated Lysosomal Permeabilization is Cathepsin B Dependent. Am J Physiol Gastrointest Liver Physiol (2002) 283(4):G947-56. doi: 10.1152/ ajpgi.00151.2002

61. McComb S, Shutinoski B, Thurston S, Cessford E, Kumar K, Sad S. Cathepsins Limit Macrophage Necroptosis Through Cleavage of Rip1 Kinase. J Immunol (Baltimore Md: 1950) (2014) 192(12):5671-8. doi: 10.4049/jimmunol.1303380

62. Zhu S-Y, Yao R-Q, Li Y-X, Zhao P-Y, Ren C, Du X-H, et al. Lysosomal Quality Control of Cell Fate: A Novel Therapeutic Target for Human Diseases. Cell Death Dis (2020) 11(9):817-. doi: 10.1038/s41419-020-03032-5

63. Crane GM, Jeffery E, Morrison SJ. Adult Haematopoietic Stem Cell Niches. Nat Rev Immunol (2017) 17(9):573-90. doi: 10.1038/nri.2017.53

64. Lewis K, Yoshimoto M, Takebe T. Fetal Liver Hematopoiesis: From Development to Delivery. Stem Cell Res Ther (2021) 12(1):139. doi: 10.1186/s13287-021-02189-w

65. Zhang Y, Gao S, Xia J, Liu F. Hematopoietic Hierarchy - An Updated Roadmap. Trends Cell Biol (2018) 28(12):976-86. doi: 10.1016/j.tcb.2018.06.001 
66. Gowen M, Lazner F, Dodds R, Kapadia R, Feild J, Tavaria M, et al. Cathepsin K Knockout Mice Develop Osteopetrosis Due to a Deficit in Matrix Degradation But Not Demineralization. J Bone Miner Res (1999) 14 (10):1654-63. doi: 10.1359/jbmr.1999.14.10.1654

67. Saez B, Ferraro F, Yusuf RZ, Cook CM, Yu VW, Pardo-Saganta A, et al. Inhibiting Stromal Cell Heparan Sulfate Synthesis Improves Stem Cell Mobilization and Enables Engraftment Without Cytotoxic Conditioning. Blood (2014) 124(19):2937-47. doi: 10.1182/blood-2014-08-593426

68. Staudt ND, Maurer A, Spring B, Kalbacher H, Aicher WK, Klein G. Processing of CXCL12 by Different Osteoblast-Secreted Cathepsins. Stem Cells Dev (2011) 21(11):1924-35. doi: 10.1089/scd.2011.0307

69. Greenbaum A, Hsu Y-MS, Day RB, Schuettpelz LG, Christopher MJ, Borgerding JN, et al. CXCL12 in Early Mesenchymal Progenitors is Required for Haematopoietic Stem-Cell Maintenance. Nature (2013) 495 (7440):227-30. doi: 10.1038/nature11926

70. Staudt ND, Aicher WK, Kalbacher H, Stevanovic S, Carmona AK, Bogyo M, et al. Cathepsin X Is Secreted by Human Osteoblasts, Digests CXCL-12 and Impairs Adhesion of Hematopoietic Stem and Progenitor Cells to Osteoblasts. Haematologica (2010) 95(9):1452-60. doi: 10.3324/ haematol.2009.018671

71. Morko J, Kiviranta R, Mulari MT, Ivaska KK, Väänänen HK, Vuorio E, et al. Overexpression of Cathepsin K Accelerates the Resorption Cycle and Osteoblast Differentiation In Vitro. Bone (2009) 44(4):717-28. doi: 10.1016/ j.bone.2008.11.019

72. Badano MN, Camicia GL, Lombardi G, Maglioco A, Cabrera G, Costa H, et al. B-Cell Lymphopoiesis Is Regulated by Cathepsin L. PloS One (2013) 8(4): e61347. doi: 10.1371/journal.pone.0061347

73. Benavides F, Venables A, Poetschke Klug H, Glasscock E, Rudensky A, Gómez $\mathrm{M}$, et al. The CD4 T Cell-Deficient Mouse Mutation Nackt (Nkt) Involves a Deletion in the Cathepsin L (CtsI) Gene. Immunogenetics (2001) 53(3):23342. doi: $10.1007 / \mathrm{s} 002510100320$

74. Monroe JG, Dorshkind K. Fate Decisions Regulating Bone Marrow and Peripheral B Lymphocyte Development. Adv Immunol (2007) 95:1-50. doi: 10.1016/S0065-2776(07)95001-4

75. Jakoš T, Pišlar A, Pečar Fonović U, Švajger U, Kos J. Cysteine Cathepsins L and X Differentially Modulate Interactions Between Myeloid-Derived Suppressor Cells and Tumor Cells. Cancer Immunol Immunother (2020) 69 (9):1869-80. doi: 10.1007/s00262-020-02592-x

76. Felbor U, Dreier L, Bryant RA, Ploegh HL, Olsen BR, Mothes W. Secreted Cathepsin L Generates Endostatin From Collagen XVIII. EMBO J (2000) 19 (6):1187-94. doi: 10.1093/emboj/19.6.1187

77. Maciewicz RA, Etherington DJ. A Comparison of Four Cathepsins (B, L, N and S) With Collagenolytic Activity From Rabbit Spleen. Biochem J (1988) 256 (2):433-40. doi: 10.1042/bj2560433

78. Radomska HS, Huettner CS, Zhang P, Cheng T, Scadden DT, Tenen DG. CCAAT/Enhancer Binding Protein Alpha Is a Regulatory Switch Sufficient for Induction of Granulocytic Development From Bipotential Myeloid Progenitors. Mol Cell Biol (1998) 18(7):4301-14. doi: 10.1128/MCB.18.7.4301

79. Chapman HA, Reilly JJ, Yee R, Grubb A. Identification of Cystatin C, a Cysteine Proteinase Inhibitor, as a Major Secretory Product of Human Alveolar Macrophages In Vitro. Am Rev Respir Dis (1990) 141(3):698-705. doi: $10.1164 /$ ajrccm/141.3.698

80. Tamura T, Thotakura P, Tanaka TS, Ko MSH, Ozato K. Identification of Target Genes and a Unique Cis Element Regulated by IRF-8 in Developing Macrophages. Blood (2005) 106(6):1938-47. doi: 10.1182/blood-2005-01-0080

81. Moshe A, Izraely S, Sagi-Assif O, Prakash R, Telerman A, Meshel T, et al. Cystatin C Takes Part in Melanoma-Microglia Cross-Talk: Possible Implications for Brain Metastasis. Clin Exp Metastasis (2018) 35(5-6):36978. doi: $10.1007 / \mathrm{s} 10585-018-9891-0$

82. Clarke AJ, Simon AK. Autophagy in the Renewal, Differentiation and Homeostasis of Immune Cells. Nat Rev Immunol (2019) 19(3):170-83. doi: 10.1038/s41577-018-0095-2

83. Zhang Y, Morgan MJ, Chen K, Choksi S, Liu Z-g. Induction of Autophagy Is Essential for Monocyte-Macrophage Differentiation. Blood (2012) 119 (12):2895-905. doi: 10.1182/blood-2011-08-372383

84. Bednarczyk M, Stege H, Grabbe S, Bros M. $\beta 2$ Integrins-Multi-Functional Leukocyte Receptors in Health and Disease. Int J Mol Sci (2020) 21(4):1402. doi: $10.3390 /$ ijms 21041402
85. Brömme D, Panwar P, Turan S. Cathepsin K Osteoporosis Trials, Pycnodysostosis and Mouse Deficiency Models: Commonalities and Differences. Expert Opin Drug Discov (2016) 11(5):457-72. doi: 10.1517/ 17460441.2016.1160884

86. Wohrer S, Knapp DJ, Copley MR, Benz C, Kent DG, Rowe K, et al. Distinct Stromal Cell Factor Combinations can Separately Control Hematopoietic Stem Cell Survival, Proliferation, and Self-Renewal. Cell Rep (2014) 7(6):195667. doi: 10.1016/j.celrep.2014.05.014

87. Bruno E, Luikart SD, Long MW, Hoffman R. Marrow-Derived Heparan Sulfate Proteoglycan Mediates the Adhesion of Hematopoietic Progenitor Cells to Cytokines. Exp Hematol (1995) 23(11):1212-7.

88. Abboud-Jarrous G, Atzmon R, Peretz T, Palermo C, Gadea BB, Joyce JA, et al. Cathepsin L Is Responsible for Processing and Activation of Proheparanase Through Multiple Cleavages of a Linker Segment*. J Biol Chem (2008) 283 (26):18167-76. doi: 10.1074/jbc.M801327200

89. Kollet O, Dar A, Shivtiel S, Kalinkovich A, Lapid K, Sztainberg Y, et al. Osteoclasts Degrade Endosteal Components and Promote Mobilization of Hematopoietic Progenitor Cells. Nat Med (2006) 12(6):657-64. doi: 10.1038/ nm1417

90. Broxmeyer HE. Chemokines in Hematopoiesis. Curr Opin Hematol (2008) 15 (1):49-58. doi: 10.1097/MOH.0b013e3282f29012

91. Terashima A, Takayanagi H. The Role of Bone Cells in Immune Regulation During the Course of Infection. Semin Immunopathol (2019) 41(5):619-26. doi: 10.1007/s00281-019-00755-2

92. Edgington-Mitchell LE, Rautela J, Duivenvoorden HM, Jayatilleke KM, van der Linden WA, Verdoes M, et al. Cysteine Cathepsin Activity Suppresses Osteoclastogenesis of Myeloid-Derived Suppressor Cells in Breast Cancer. Oncotarget (2015) 6(29):8-10. doi: 10.18632/oncotarget.4714

93. Jacome-Galarza C, Soung DY, Adapala NS, Pickarski M, Sanjay A, Duong LT, et al. Altered Hematopoietic Stem Cell and Osteoclast Precursor Frequency in Cathepsin K Null Mice. J Cell Biochem (2014) 115(8):1449-57. doi: 10.1002/ jcb. 24801

94. Oostendorp RA, Robin C, Steinhoff C, Marz S, Bräuer R, Nuber UA, et al. Long-Term Maintenance of Hematopoietic Stem Cells Does Not Require Contact With Embryo-Derived Stromal Cells in Cocultures. Stem Cells (Dayton Ohio) (2005) 23(6):842-51. doi: 10.1634/stemcells.2004-0120

95. Oostendorp RA, Harvey KN, Kusadasi N, de Bruijn MF, Saris C, Ploemacher RE, et al. Stromal Cell Lines From Mouse Aorta-Gonads-Mesonephros Subregions are Potent Supporters of Hematopoietic Stem Cell Activity. Blood (2002) 99(4):1183-9. doi: 10.1182/blood.V99.4.1183

96. Hausinger R, Hackl M, Jardon-Alvarez A, Kehr M, Marquez SR, Hettler F, et al. Cathepsin K Maintains the Number of Lymphocytes In Vivo. bioRxiv (2020) 9:2020.03.04.977496. doi: 10.1101/2020.03.04.977496

97. Lalanne AI, Moraga I, Hao Y, Pereira JP, Alves NL, Huntington ND, et al. CpG Inhibits Pro-B Cell Expansion Through a Cathepsin B-Dependent Mechanism. J Immunol (2010) 184(10):5678-85. doi: 10.4049/jimmunol.0903854

98. Blum JS, Cresswell P. Role for Intracellular Proteases in the Processing and Transport of Class II HLA Antigens. Proc Natl Acad Sci U S A (1988) 85 (11):3975-9. doi: 10.1073/pnas.85.11.3975

99. Kitamura H, Kamon H, Sawa S, Park SJ, Katunuma N, Ishihara K, et al. IL-6STAT3 Controls Intracellular MHC Class II Alphabeta Dimer Level Through Cathepsin S Activity in Dendritic Cells. Immunity (2005) 23(5):491-502. doi: 10.1016/j.immuni.2005.09.010

100. Vray B, Hartmann S, Hoebeke J. Immunomodulatory Properties of Cystatins. Cell Mol Life Sci (2002) 59(9):1503-12. doi: 10.1007/s00018002-8525-4

101. Nakagawa T, Roth W, Wong P, Nelson A, Farr A, Deussing J, et al. Cathepsin L: Critical Role in Ii Degradation and CD4 T Cell Selection in the Thymus. Science (New York NY) (1998) 280(5362):450-3. doi: 10.1126/ science.280.5362.450

102. Honey K, Nakagawa T, Peters C, Rudensky A. Cathepsin L Regulates CD4+ T Cell Selection Independently of its Effect on Invariant Chain: A Role in the Generation of Positively Selecting Peptide Ligands. J Exp Med (2002) 195 (10):1349-58. doi: 10.1084/jem.20011904

103. Tolosa E, Li W, Yasuda Y, Wienhold W, Denzin LK, Lautwein A, et al. Cathepsin V Is Involved in the Degradation of Invariant Chain in Human Thymus and Is Overexpressed in Myasthenia Gravis. J Clin Invest (2003) 112 (4):517-26. doi: 10.1172/JCI200318028 
104. Lombardi G, Burzyn D, Mundiñano J, Berguer P, Bekinschtein P, Costa H, et al. Cathepsin-L Influences the Expression of Extracellular Matrix in Lymphoid Organs and Plays a Role in the Regulation of Thymic Output and of Peripheral T Cell Number. J Immunol (2005) 174(11):7022-32. doi: 10.4049/jimmunol.174.11.7022

105. Blondeau X, Vidmar SL, Emod I, Pagano M, Turk V, Keil-Dlouha V. Generation of Matrix-Degrading Proteolytic System From Fibronectin by Cathepsins B, G, H and L. Biol Chem Hoppe-Seyler (1993) 374(8):651-6. doi: 10.1515/bchm3.1993.374.7-12.651

106. Guinec N, Dalet-Fumeron V, Pagano M. "In Vitro" Study of Basement Membrane Degradation by the Cysteine Proteinases, Cathepsins B, B-Like and L. Digestion of Collagen IV, Laminin, Fibronectin, and Release of Gelatinase Activities From Basement Membrane Fibronectin. Biol Chem Hoppe-Seyler (1993) 374(12):1135-46. doi: 10.1515/bchm3.1993.374.7-12.1135

107. Schnepel J, Tschesche H. The Proteolytic Activity of the Recombinant Cryptic Human Fibronectin Type IV Collagenase From E. Coli Expression. J Protein Chem (2000) 19(8):685-92. doi: 10.1023/ A:1007104420017

108. Gendron S, Couture J, Aoudjit F. Integrin Alpha2betal Inhibits FasMediated Apoptosis in T Lymphocytes by Protein Phosphatase 2ADependent Activation of the MAPK/ERK Pathway. J Biol Chem (2003) 278(49):48633-43. doi: 10.1074/jbc.M305169200

109. Tschoetschel U, Schwing J, Frosch S, Schmitt E, Schuppan D, Reske-Kunz AB. Modulation of Proliferation and Lymphokine Secretion of Murine CD4+ T Cells and Cloned Th1 Cells by Proteins of the Extracellular Matrix. Int Immunol (1997) 9(1):147-59. doi: 10.1093/intimm/9.1.147

110. Honey K, Benlagha K, Beers C, Forbush K, Teyton L, Kleijmeer MJ, et al. Thymocyte Expression of Cathepsin L Is Essential for NKT Cell Development. Nat Immunol (2002) 3(11):1069-74. doi: 10.1038/ni844

111. Klibi J, Benlagha K. Cortical Thymocytes Along With Their Selecting Ligands Are Required for the Further Thymic Maturation of NKT Cells in Mice. Front Immunol (2020) 11:815. doi: 10.3389/fimmu.2020.00815

112. Sałkowska A, Karaś K, Karwaciak I, Walczak-Drzewiecka A, Krawczyk M, Sobalska-Kwapis M, et al. Identification of Novel Molecular Markers of Human Th17 Cells. Cells (2020) 9(7):1611. doi: 10.3390/cells9071611

113. Hou L, Cooley J, Swanson R, Ong PC, Pike RN, Bogyo M, et al. The Protease Cathepsin L Regulates Th17 Cell Differentiation. J Autoimmun (2015) 65:5663. doi: 10.1016/j.jaut.2015.08.006

114. Tuomela S, Salo V, Tripathi SK, Chen Z, Laurila K, Gupta B, et al. Identification of Early Gene Expression Changes During Human Th17 Cell Differentiation. Blood (2012) 119(23):e151-60. doi: 10.1182/blood2012-01-407528

115. Asagiri M, Hirai T, Kunigami T, Kamano S, Gober HJ, Okamoto K, et al. Cathepsin K-Dependent Toll-Like Receptor 9 Signaling Revealed in Experimental Arthritis. Science (New York NY) (2008) 319(5863):624-7. doi: 10.1126/science. 1150110

116. Hirai T, Kanda T, Sato K, Takaishi M, Nakajima K, Yamamoto M, et al. Cathepsin K Is Involved in Development of Psoriasis-Like Skin Lesions Through TLR-Dependent Th17 Activation. J Immunol (2013) 190(9):480511. doi: 10.4049 /jimmunol.1200901

117. Dekita M, Wu Z, Ni J, Zhang X, Liu Y, Yan X, et al. Cathepsin S Is Involved in Th17 Differentiation Through the Upregulation of IL-6 by Activating PAR-2 After Systemic Exposure to Lipopolysaccharide From Porphyromonas Gingivalis. Front Pharmacol (2017) 8:470. doi: 10.3389/fphar.2017.00470

118. Jacobson LS, Lima HJr., Goldberg MF, Gocheva V, Tsiperson V, Sutterwala FS, et al. Cathepsin-Mediated Necrosis Controls the Adaptive Immune Response by Th2 (T Helper Type 2)-Associated Adjuvants. J Biol Chem (2013) 288(11):7481-91. doi: 10.1074/jbc.M112.400655

119. Zhou Y, Chen H, Liu L, Yu X, Sukhova GK, Yang M, et al. Cathepsin K Deficiency Ameliorates Systemic Lupus Erythematosus-Like Manifestations in Faslpr Mice. J Immunol (2017) 198(5):1846-54. doi: 10.4049/jimmunol.1501145

120. Martino S, Tiribuzi R, Ciraci E, Makrypidi G, D’Angelo F, di Girolamo I, et al. Coordinated Involvement of Cathepsins S, D and Cystatin C in the Commitment of Hematopoietic Stem Cells to Dendritic Cells. Int J Biochem Cell Biol (2011) 43(5):775-83. doi: 10.1016/j.biocel.2011.02.001

121. Gupta S, Singh RK, Dastidar S, Ray A. Cysteine Cathepsin S as an Immunomodulatory Target: Present and Future Trends. Expert Opin Ther Targets (2008) 12(3):291-9. doi: 10.1517/14728222.12.3.291
122. Yang M, Liu J, Shao J, Qin Y, Ji Q, Zhang X, et al. Cathepsin S-Mediated Autophagic Flux in Tumor-Associated Macrophages Accelerate Tumor Development by Promoting M2 Polarization. Mol Cancer (2014) 13 (1):43-. doi: 10.1186/1476-4598-13-43

123. Alam S, Liu Q, Liu S, Liu Y, Zhang Y, Yang X, et al. Up-Regulated Cathepsin C Induces Macrophage M1 Polarization Through FAK-Triggered P38 MAPK/NF-kappaB Pathway. Exp Cell Res (2019) 382(2):111472-. doi: 10.1016/j.yexcr.2019.06.017

124. HerĂas V, Biessen EAL, Beckers C, Delsing D, Liao M, Daemen MJ, et al. Leukocyte Cathepsin C Deficiency Attenuates Atherosclerotic Lesion Progression by Selective Tuning of Innate and Adaptive Immune Responses. Arterioscler Thromb Vasc Biol (2015) 35(1):79-86. doi: 10.1161/ATVBAHA.114.304292

125. Welsh RM, Selin LK. No One is Naive: The Significance of Heterologous TCell Immunity. Nat Rev Immunol (2002) 2(6):417-26. doi: 10.1038/nri820

126. Byrne SM, Aucher A, Alyahya S, Elder M, Olson ST, Davis DM, et al. Cathepsin B Controls the Persistence of Memory CD8+ T Lymphocytes. J Immunol (2012) 189(3):1133-43. doi: 10.4049/jimmunol.1003406

127. Qi X, Man SM, Malireddi RKS, Karki R, Lupfer C, Gurung P, et al. Cathepsin B Modulates Lysosomal Biogenesis and Host Defense Against Francisella Novicida Infection. J Exp Med (2016) 213(10):2081-97. doi: 10.1084/jem.20151938

128. Klann JE, Remedios KA. Talin Plays a Critical Role in the Maintenance of the Regulatory T Cell Pool. J Immunol (2017) 198(12):4639-51. doi: 10.4049/ jimmunol.1601165

129. Zhang $\mathrm{Y}$, Wang H. Integrin Signalling and Function in Immune Cells. Immunology (2012) 135(4):268-75. doi: 10.1111/j.1365-2567.2011.03549.x

130. Kos J, Jevnikar Z, Obermajer N. The Role of Cathepsin X in Cell Signaling. Cell Adh Migr (2009) 3(2):164-6. doi: 10.4161/cam.3.2.7403

131. Turk B, Turk D, Turk V. Protease Signalling: The Cutting Edge. EMBO J (2012) 31(7):1630-43. doi: 10.1038/emboj.2012.42

132. Turk B, Turk D, Salvesen GS. Regulating Cysteine Protease Activity: Essential Role of Protease Inhibitors as Guardians and Regulators. Curr Pharm Des (2002) 8(18):1623-37. doi: 10.2174/1381612023394124

133. Cygler M, Mort JS. Proregion Structure of Members of the Papain Superfamily. Mode of Inhibition of Enzymatic Activity. Biochimie (1997) 79(11):645-52. doi: 10.1016/S0300-9084(97)83497-9

134. Rawlings ND, Tolle DP, Barrett AJ. Evolutionary Families of Peptidase Inhibitors. Biochem J (2004) 378(Pt 3):705-16. doi: 10.1042/bj20031825

135. Turk V, Bode W. The Cystatins: Protein Inhibitors of Cysteine Proteinases. FEBS Lett (1991) 285(2):213-9. doi: 10.1016/0014-5793(91)80804-C

136. Turk V, Stoka V, Turk D. Cystatins: Biochemical and Structural Properties, and Medical Relevance. Front Biosci (2008) 13:5406-20. doi: 10.2741/3089

137. Breznik B, Mitrović A T, Lah T, Kos J. Cystatins in Cancer Progression: More Than Just Cathepsin Inhibitors. Biochimie (2019) 166:233-50. doi: 10.1016/ j.biochi.2019.05.002

138. Pečar Fonovic U, Perišić Nanut M, Zidar N, Lenarčič B, Kos J. The Carboxypeptidase Activity of Cathepsin X is Not Controlled by Endogenous Inhibitors. Acta Chim Slov (2019) 65:58-61. doi: 10.17344/ acsi.2018.4427

139. Rawlings ND, Barrett AJ. Evolution of Proteins of the Cystatin Superfamily. $J$ Mol Evol (1990) 30(1):60-71. doi: 10.1007/BF02102453

140. Fossum K, Whitaker JR. Ficin and Papain Inhibitor From Chicken Egg White. Arch Biochem Biophys (1968) 125(1):367-75. doi: 10.1016/0003-9861 (68) $90672-3$

141. Nakanishi S. Substance P Precursor and Kininogen: Their Structures, Gene Organizations, and Regulation. Physiol Rev (1987) 67(4):1117-42. doi: 10.1152/physrev.1987.67.4.1117

142. Nordahl EA, Rydengård V, Mörgelin M, Schmidtchen A. Domain 5 of High Molecular Weight Kininogen Is Antibacterial. J Biol Chem (2005) 280 (41):34832-9. doi: 10.1074/jbc.M507249200

143. Lenarcic B, Bevec T. Thyropins-new Structurally Related Proteinase Inhibitors. Biol Chem (1998) 379(2):105-11.

144. Molina F, Bouanani M, Pau B, Granier C. Characterization of the Type-1 Repeat From Thyroglobulin, a Cysteine-Rich Module Found in Proteins From Different Families. Eur J Biochem (1996) 240(1):125-33. doi: 10.1111/ j.1432-1033.1996.0125h.x

145. Pungercic G, Dolenc I, Dolinar M, Bevec T, Jenko S, Kolaric S, et al. Individual Recombinant Thyroglobulin Type-1 Domains Are Substrates 
for Lysosomal Cysteine Proteinases. Biol Chem (2002) 383(11):1809-12. doi: 10.1515/BC.2002.202

146. Meh P, Pavsic M, Turk V, Baici A, Lenarcic B. Dual ConcentrationDependent Activity of Thyroglobulin Type-1 Domain of Testican: Specific Inhibitor and Substrate of Cathepsin L. Biol Chem (2005) 386(1):75-83. doi: 10.1515/BC.2005.010

147. Bevec T, Stoka V, Pungercic G, Dolenc I, Turk V. Major Histocompatibility Complex Class II-Associated P41 Invariant Chain Fragment Is a Strong Inhibitor of Lysosomal Cathepsin L. J Exp Med (1996) 183(4):1331-8. doi: 10.1084/jem.183.4.1331

148. Bocock JP, Edgell CJ, Marr HS, Erickson AH. Human Proteoglycan Testican1 Inhibits the Lysosomal Cysteine Protease Cathepsin L. Eur J Biochem (2003) 270(19):4008-15. doi: 10.1046/j.1432-1033.2003.03789.x

149. Nakada M, Yamada A, Takino T, Miyamori H, Takahashi T, Yamashita J, et al. Suppression of Membrane-Type 1 Matrix Metalloproteinase (MMP)Mediated MMP-2 Activation and Tumor Invasion by Testican 3 and its Splicing Variant Gene Product, N-Tes. Cancer Res (2001) 61(24):8896-902.

150. Yamashita M, Konagaya S. A Novel Cysteine Protease Inhibitor of the Egg of Chum Salmon, Containing a Cysteine-Rich Thyroglobulin-Like Motif. J Biol Chem (1996) 271(3):1282-4. doi: 10.1074/jbc.271.3.1282

151. Lenarcic B, Ritonja A, Strukelj B, Turk B, Turk V. Equistatin, a New Inhibitor of Cysteine Proteinases From Actinia Equina, Is Structurally Related to Thyroglobulin Type-1 Domain. J Biol Chem (1997) 272(21):13899-903. doi: 10.1074/jbc.272.21.13899

152. Lenarcic B, Krishnan G, Borukhovich R, Ruck B, Turk V, Moczydlowski E. Saxiphilin, a Saxitoxin-Binding Protein With Two Thyroglobulin Type 1 Domains, is an Inhibitor of Papain-Like Cysteine Proteinases. J Biol Chem (2000) 275(20):15572-7. doi: 10.1074/jbc.M001406200

153. Lenarcic B, Turk V. Thyroglobulin Type-1 Domains in Equistatin Inhibit Both Papain-Like Cysteine Proteinases and Cathepsin D. J Biol Chem (1999) 274(2):563-6. doi: 10.1074/jbc.274.2.563

154. Ogrinc T, Dolenc I, Ritonja A, Turk V. Purification of the Complex of Cathepsin L and the MHC Class II-Associated Invariant Chain Fragment From Human Kidney. FEBS Lett (1993) 336(3):555-9. doi: 10.1016/00145793(93)80875-U

155. Bonnet F, Perin JP, Maillet P, Jolles P, Alliel PM. Characterization of a Human Seminal Plasma Glycosaminoglycan-Bearing Polypeptide. Biochem J (1992) 288(Pt 2):565-9. doi: 10.1042/bj2880565

156. Timpl R, Dziadek M, Fujiwara S, Nowack H, Wick G. Nidogen: A New, SelfAggregating Basement Membrane Protein. Eur J Biochem (1983) 137 (3):455-65. doi: 10.1111/j.1432-1033.1983.tb07849.x

157. Pozzi A, Yurchenco PD, Iozzo RV. The Nature and Biology of Basement Membranes. Matrix Biol (2017) 57-8:1-11. doi: 10.1016/j.matbio. 2016.12.009

158. Ashton-Rickardt PG. An Emerging Role for Serine Protease Inhibitors in $\mathrm{T}$ Lymphocyte Immunity and Beyond. Immunol Lett (2013) 152(1):65-76. doi: 10.1016/j.imlet.2013.04.004

159. Liu N, Raja SM, Zazzeroni F, Metkar SS, Shah R, Zhang M, et al. NF-kappaB Protects From the Lysosomal Pathway of Cell Death. EMBO J (2003) 22 (19):5313-22. doi: 10.1093/emboj/cdg510

160. Al-Khunaizi M, Luke CJ, Askew YS, Pak SC, Askew DJ, Cataltepe S, et al. The Serpin SQN-5 Is a Dual Mechanistic-Class Inhibitor of Serine and Cysteine Proteinases. Biochemistry (2002) 41(9):3189-99. doi: 10.1021/bi015999x

161. Schick C, Pemberton PA, Shi GP, Kamachi Y, Cataltepe S, Bartuski AJ, et al. Cross-Class Inhibition of the Cysteine Proteinases Cathepsins K, L, and S by the Serpin Squamous Cell Carcinoma Antigen 1: A Kinetic Analysis. Biochemistry (1998) 37(15):5258-66. doi: 10.1021/bi972521d

162. Welss T, Sun J, Irving JA, Blum R, Smith AI, Whisstock JC, et al. Hurpin Is a Selective Inhibitor of Lysosomal Cathepsin L and Protects Keratinocytes From Ultraviolet-Induced Apoptosis. Biochemistry (2003) 42(24):7381-9. doi: $10.1021 / \mathrm{bi} 027307 \mathrm{q}$

163. Annand RR, Dahlen JR, Sprecher CA, De Dreu P, Foster DC, Mankovich JA, et al. Caspase-1 (Interleukin-1beta-Converting Enzyme) Is Inhibited by the Human Serpin Analogue Proteinase Inhibitor 9. Biochem J (1999) 342 Pt 3 (Pt 3):655-65. doi: 10.1042/bj3420655

164. Pierre P, Mellman I. Developmental Regulation of Invariant Chain Proteolysis Controls MHC Class II Trafficking in Mouse Dendritic Cells. Cell (1998) 93(7):1135-45. doi: 10.1016/S0092-8674(00)81458-0
165. Kopitar-Jerala N. The Role of Cysteine Proteinases and Their Inhibitors in the Host-Pathogen Cross Talk. Curr Protein Pept Sci (2012) 13(8):767-75. doi: $10.2174 / 138920312804871102$

166. Clark GJ, Angel N, Kato M, López JA, MacDonald K, Vuckovic S, et al. The Role of Dendritic Cells in the Innate Immune System. Microbes Infect (2000) 2(3):257-72. doi: 10.1016/S1286-4579(00)00302-6

167. Mellman I, Steinman RM. Dendritic Cells: Specialized and Regulated Antigen Processing Machines. Cell (2001) 106(3):255-8. doi: 10.1016/ S0092-8674(01)00449-4

168. Riese RJ, Wolf PR, Brömme D, Natkin LR, Villadangos JA, Ploegh HL, et al. Essential Role for Cathepsin S in MHC Class II-Associated Invariant Chain Processing and Peptide Loading. Immunity (1996) 4(4):357-66. doi: 10.1016/ S1074-7613(00)80249-6

169. Hashimoto SI, Suzuki T, Nagai S, Yamashita T, Toyoda N, Matsushima K. Identification of Genes Specifically Expressed in Human Activated and Mature Dendritic Cells Through Serial Analysis of Gene Expression. Blood (2000) 96(6):2206-14. doi: 10.1182/blood.V96.6.2206

170. Zavasnik-Bergant T, Repnik U, Schweiger A, Romih R, Jeras M, Turk V, et al. Differentiation- and Maturation-Dependent Content, Localization, and Secretion of Cystatin C in Human Dendritic Cells. J Leukoc Biol (2005) 78 (1):122-34. doi: 10.1189/jlb.0804451

171. Zavašnik-Bergant T, Bergant M, Jeras M, Griffiths G. Different Localisation of Cystatin C in Immature and Mature Dendtritic Cells. Radiol Oncol (2006) 40:183-8.

172. El-Sukkari D, Wilson NS, Hakansson K, Steptoe RJ, Grubb A, Shortman K, et al. The Protease Inhibitor Cystatin C Is Differentially Expressed Among Dendritic Cell Populations, But Does Not Control Antigen Presentation. J Immunol (2003) 171(10):5003-11. doi: 10.4049/jimmunol.171.10.5003

173. Zhang W, Zi M, Sun L, Wang F, Chen S, Zhao Y, et al. Cystatin C Regulates Major Histocompatibility Complex-II-Peptide Presentation and Extracellular Signal-Regulated Kinase-Dependent Polarizing Cytokine Production by Bone Marrow-Derived Dendritic Cells. Immunol Cell Biol (2019) 97(10):916-30. doi: 10.1111/imcb.12290

174. Chen S, Liu L, Zhang W, Sun L, Wang F, Zhao Y, et al. Suppressed Dendritic Cell Functions by Cystatin C Lead to Compromised Immunity In Vivo. Cell Immunol (2020) 349:104049. doi: 10.1016/j.cellimm.2020.104049

175. Bossowska-Nowicka M, Mielcarska MB, Romaniewicz M, Kaczmarek MM, Gregorczyk-Zboroch KP, Struzik J, et al. Ectromelia Virus Suppresses Expression of Cathepsins and Cystatins in Conventional Dendritic Cells to Efficiently Execute the Replication Process. BMC Microbiol (2019) 19(1):92. doi: 10.1186/s12866-019-1471-1

176. Alvarez-Fernandez M, Liang YH, Abrahamson M, Su XD. Crystal Structure of Human Cystatin D, a Cysteine Peptidase Inhibitor With Restricted Inhibition Profile. J Biol Chem (2005) 280(18):18221-8. doi: 10.1074/ jbc.M411914200

177. Shi GP, Bryant RA, Riese R, Verhelst S, Driessen C, Li Z, et al. Role for Cathepsin $\mathrm{F}$ in Invariant Chain Processing and Major Histocompatibility Complex Class II Peptide Loading by Macrophages. J Exp Med (2000) 191 (7):1177-86. doi: 10.1084/jem.191.7.1177

178. Perišić Nanut M, Sabotič J, Jewett A, Kos J. Cysteine Cathepsins as Regulators of the Cytotoxicity of NK and T Cells. Front Immunol (2014) 5:616. doi: 10.3389/fimmu.2014.00616

179. Chowdhury D, Lieberman J. Death by a Thousand Cuts: Granzyme Pathways of Programmed Cell Death. Annu Rev Immunol (2008) 26:389420. doi: 10.1146/annurev.immunol.26.021607.090404

180. Prunk M, Nanut MP, Sabotic J, Svajger U, Kos J. Increased Cystatin F Levels Correlate With Decreased Cytotoxicity of Cytotoxic T Cells. Radiol Oncol (2019) 53(1):57-68. doi: 10.2478/raon-2019-0007

181. Konjar S, Sutton VR, Hoves S, Repnik U, Yagita H, Reinheckel T, et al. Human and Mouse Perforin are Processed in Part Through Cleavage by the Lysosomal Cysteine Proteinase Cathepsin L. Immunology (2010) 131(2):25767. doi: 10.1111/j.1365-2567.2010.03299.x

182. Pham CT, Ley TJ. Dipeptidyl Peptidase I Is Required for the Processing and Activation of Granzymes A and B In Vivo. Proc Natl Acad Sci U S A (1999) 96(15):8627-32. doi: 10.1073/pnas.96.15.8627

183. D’Angelo ME, Bird PI, Peters C, Reinheckel T, Trapani JA, Sutton VR. Cathepsin H Is an Additional Convertase of Pro-Granzyme B. J Biol Chem (2010) 285(27):20514-9. doi: 10.1074/jbc.M109.094573 
184. Chan CB, Abe M, Hashimoto N, Hao C, Williams IR, Liu X, et al. Mice Lacking Asparaginyl Endopeptidase Develop Disorders Resembling Hemophagocytic Syndrome. Proc Natl Acad Sci U S A (2009) 106(2):468-73.

185. Langerholc T, Zavasnik-Bergant V, Turk B, Turk V, Abrahamson M, Kos J. Inhibitory Properties of Cystatin F and its Localization in U937 Promonocyte Cells. FEBS J (2005) 272(6):1535-45. doi: 10.1111/j.17424658.2005.04594.x

186. Hamilton G, Colbert JD, Schuettelkopf AW, Watts C. Cystatin F Is a Cathepsin C-Directed Protease Inhibitor Regulated by Proteolysis. EMBO J (2008) 27(3):499-508. doi: 10.1038/sj.emboj.7601979

187. Colbert JD, Matthews SP, Kos J, Watts C. Internalization of Exogenous Cystatin F Supresses Cysteine Proteases and Induces the Accumulation of Single-Chain Cathepsin L by Multiple Mechanisms. J Biol Chem (2011) 286 (49):42082-90. doi: 10.1074/jbc.M111.253914

188. Perišić Nanut M, Sabotič J, Švajger U, Jewett A, Kos J. Cystatin F Affects Natural Killer Cell Cytotoxicity. Front Immunol (2017) 8:1459. doi: 10.3389/ fimmu.2017.01459

189. Mingo Pulido AD, Gregorio ED, Chandra S, Colell A, Morales A, Kronenberg M, et al. Differential Role of Cathepsins S and B In Hepatic APC-Mediated NKT Cell Activation and Cytokine Secretion. Front Immunol (2018) 9:391. doi: 10.3389/fimmu.2018.00391

190. Long H, Liao W, Wang L, Lu Q. A Player and Coordinator: The Versatile Roles of Eosinophils in the Immune System. Transfus Med Hemother (2016) 43(2):96-108. doi: 10.1159/000445215

191. Matthews SP, McMillan SJ, Colbert JD, Lawrence RA, Watts C. Cystatin F Ensures Eosinophil Survival by Regulating Granule Biogenesis. Immunity (2016) 44(4):795-806. doi: 10.1016/j.immuni.2016.03.003

192. Yan B, Lou H, Wang Y, Li Y, Meng Y, Qi S, et al. Epithelium-Derived Cystatin SN Enhances Eosinophil Activation and Infiltration Through IL-5 in Patients With Chronic Rhinosinusitis With Nasal Polyps. J Allergy Clin Immunol (2019) 144(2):455-69. doi: 10.1016/j.jaci.2019.03.026

193. Malech HL, Deleo FR, Quinn MT. The Role of Neutrophils in the Immune System: An Overview. Methods Mol Biol (2014) 1124:3-10. doi: 10.1007/9781-62703-845-4_1

194. Adkison AM, Raptis SZ, Kelley DG, Pham CT. Dipeptidyl Peptidase I Activates Neutrophil-Derived Serine Proteases and Regulates the Development of Acute Experimental Arthritis. J Clin Invest (2002) 109 (3):363-71. doi: 10.1172/JCI0213462

195. Hamon Y, Legowska M, Hervé V, Dallet-Choisy S, Marchand-Adam S, Vanderlynden L, et al. Neutrophilic Cathepsin C Is Maturated by a Multistep Proteolytic Process and Secreted by Activated Cells During Inflammatory Lung Diseases. J Biol Chem (2016) 291(16):8486-99. doi: 10.1074/ jbc.M115.707109

196. Leung-Tack J, Tavera C, Martinez J, Colle A. Neutrophil Chemotactic Activity Is Modulated by Human Cystatin C, an Inhibitor of Cysteine Proteases. Inflammation (1990) 14(3):247-58. doi: 10.1007/BF00915809

197. Ma WT, Gao F, Gu K, Chen DK. The Role of Monocytes and Macrophages in Autoimmune Diseases: A Comprehensive Review. Front Immunol (2019) 10:1140. doi: 10.3389/fimmu.2019.01140

198. Dautović E, Perišić Nanut M, Softić A, Kos J. The Transcription Factor C/ EBP $\alpha$ Controls the Role of Cystatin F During the Differentiation of Monocytes to Macrophages. Eur J Cell Biol (2018) 97:463-73. doi: 10.1016/j.ejcb.2018.07.002

199. Gren ST, Janciauskiene S, Sandeep S, Jonigk D, Kvist PH, Gerwien JG, et al. The Protease Inhibitor Cystatin C Down-Regulates the Release of IL- $\beta$ and TNF- $\alpha$ in Lipopolysaccharide Activated Monocytes. J Leukoc Biol (2016) 100 (4):811-22. doi: 10.1189/jlb.5A0415-174R

200. Hashimoto S, Suzuki T, Dong HY, Nagai S, Yamazaki N, Matsushima K. Serial Analysis of Gene Expression in Human Monocyte-Derived Dendritic Cells. Blood (1999) 94(3):845-52. doi: 10.1182/blood.V94.3.845. 415k09_845 852

201. Suzuki T, Hashimoto S, Toyoda N, Nagai S, Yamazaki N, Dong HY, et al. Comprehensive Gene Expression Profile of LPS-Stimulated Human Monocytes by SAGE. Blood (2000) 96(7):2584-91. doi: 10.1182/blood.V96.7.2584

202. Park B, Brinkmann MM, Spooner E, Lee CC, Kim YM, Ploegh HL. Proteolytic Cleavage in an Endolysosomal Compartment Is Required for Activation of Toll-Like Receptor 9. Nat Immunol (2008) 9(12):1407-14. doi: 10.1038/ni. 1669
203. Ohashi K, Naruto M, Nakaki T, Sano E. Identification of Interleukin-8 Converting Enzyme as Cathepsin L. Biochim Biophys Acta (2003) 1649 (1):30-9. doi: 10.1016/S1570-9639(03)00152-3

204. Kos J, Nanut MP, Prunk M, Sabotič J, Dautović E, Jewett A. Cystatin F as a Regulator of Immune Cell Cytotoxicity. Cancer Immunol Immunother (2018) 67(12):1931-8. doi: 10.1007/s00262-018-2165-5

205. Ha SD, Martins A, Khazaie K, Han J, Chan BM, Kim SO. Cathepsin B Is Involved in the Trafficking of TNF-Alpha-Containing Vesicles to the Plasma Membrane in Macrophages. J Immunol (2008) 181(1):690-7. doi: 10.4049/ jimmunol.181.1.690

206. Zavasnik-Bergant T. Cystatin Protease Inhibitors and Immune Functions. Front Biosci (2008) 13:4625-37. doi: 10.2741/3028

207. Kos J, Vižin T, Fonović UP, Pišlar A. Intracellular Signaling by Cathepsin X: Molecular Mechanisms and Diagnostic and Therapeutic Opportunities in Cancer. Semin Cancer Biol (2015) 31:76-83. doi: 10.1016/j.semcancer. 2014.05.001

208. Magister S, Obermajer N, Mirković B, Svajger U, Renko M, Softić A, et al. Regulation of Cathepsins S and L by Cystatin F During Maturation of Dendritic Cells. Eur J Cell Biol (2012) 91(5):391-401. doi: 10.1016/j.ejcb.2012.01.001

209. Michallet MC, Saltel F, Preville X, Flacher M, Revillard JP, Genestier L. Cathepsin-B-Dependent Apoptosis Triggered by Antithymocyte Globulins: A Novel Mechanism of T-Cell Depletion. Blood (2003) 102(10):3719-26. doi: 10.1182/blood-2003-04-1075

210. Michallet M-C, Saltel F, Flacher M, Revillard J-P, Genestier L. CathepsinDependent Apoptosis Triggered by Supraoptimal Activation of $\mathrm{T}$ Lymphocytes: A Possible Mechanism of High Dose Tolerance. J Immunol (2004) 172(9):5405-14. doi: 10.4049/jimmunol.172.9.5405

211. Kim SJ, SchĂatzle S, Ahmed SS, Haap W, Jang SH, Gregersen PK, et al. Increased Cathepsin $S$ in Prdmlầ $/ \hat{A}^{\wedge}$ Dendritic Cells Alters the TFH Cell Repertoire and Contributes to Lupus. Nat Immunol (2017) 18(9):1016-24. doi: $10.1038 /$ ni.3793

212. van Eijk M, de Groot C. Germinal Center B Cell Apoptosis Requires Both Caspase and Cathepsin Activity. J Immunol (1999) 163(5):2478-82.

213. van Nierop K, Muller FJ, Stap J, Van Noorden CJ, van Eijk M, de Groot C. Lysosomal Destabilization Contributes to Apoptosis of Germinal Center BLymphocytes. J Histochem Cytochem (2006) 54(12):1425-35. doi: 10.1369/ jhc.6A6967.2006

214. Kaur K, Nanut MP, Ko MW, Safaie T, Kos J, Jewett A. Natural Killer Cells Target and Differentiate Cancer Stem-Like Cells/Undifferentiated Tumors: Strategies to Optimize Their Growth and Expansion for Effective Cancer Immunotherapy. Curr Opin Immunol (2018) 51:170-80. doi: 10.1016/ j.coi.2018.03.022

215. Magister Š, Tseng H-C, Bui VT, Kos J, Jewett A. Regulation of Split Anergy in Natural Killer Cells by Inhibition of Cathepsins $\mathrm{C}$ and $\mathrm{H}$ and Cystatin $\mathrm{F}$. Oncotarget (2015) 6(26):22310-27. doi: 10.18632/oncotarget.4208

216. Prunk M, Perišić Nanut M. Extracellular Cystatin F Is Internalised by Cytotoxic T Lymphocytes and Decreases Their Cytotoxicity. Cancers (2020) 12(12):3660. doi: 10.3390/cancers 12123660

217. Fiebiger E, Meraner P, Weber E, Fang IF, Stingl G, Ploegh H, et al. Cytokines Regulate Proteolysis in Major Histocompatibility Complex Class IIDependent Antigen Presentation by Dendritic Cells. J Exp Med (2001) 193 (8):881-92. doi: 10.1084/jem.193.8.881

218. Beers C, Honey K, Fink S, Forbush K, Rudensky A. Differential Regulation of Cathepsin S and Cathepsin L in Interferon Gamma-Treated Macrophages. J Exp Med (2003) 197(2):169-79. doi: 10.1084/jem.20020978

219. Rutella S, Danese S, Leone G. Tolerogenic Dendritic Cells: Cytokine Modulation Comes of Age. Blood (2006) 108(5):1435-40. doi: 10.1182/ blood-2006-03-006403

220. Chan LL, Cheung BK, Li JC, Lau AS. A Role for STAT3 and Cathepsin S in IL-10 Down-Regulation of IFN-Gamma-Induced MHC Class II Molecule on Primary Human Blood Macrophages. J Leukoc Biol (2010) 88(2):303-11. doi: 10.1189/jlb.1009659

221. Cuervo AM, Dice JF. How do Intracellular Proteolytic Systems Change With Age? Front Biosci (1998) 3:d25-43. doi: 10.2741/A264

222. Kurz DJ, Decary S, Hong Y, Erusalimsky JD. Senescence-Associated (Beta)Galactosidase Reflects an Increase in Lysosomal Mass During Replicative Ageing of Human Endothelial Cells. J Cell Sci (2000) 113(Pt 20):3613-22. doi: $10.1242 /$ jcs.113.20.3613 
223. Ono K, Kim SO, Han J. Susceptibility of Lysosomes to Rupture Is a Determinant for Plasma Membrane Disruption in Tumor Necrosis Factor Alpha-Induced Cell Death. Mol Cell Biol (2003) 23(2):665-76. doi: 10.1128/ MCB.23.2.665-676.2003

224. Kerschan-Schindl K, Hawa G, Kudlacek S, Woloszczuk W, Pietschmann P. Serum Levels of Cathepsin K Decrease With Age in Both Women and Men. Exp Gerontol (2005) 40(6):532-5. doi: 10.1016/j.exger.2005.04.001

225. Panwar P, Butler GS, Jamroz A, Azizi P, Overall CM, Brömme D. Aging-Associated Modifications of Collagen Affect its Degradation by Matrix Metalloproteinases. Matrix Biol (2018) 65:30-44. doi: 10.1016/j.matbio.2017.06.004

226. Wang X, Hua R, Ahsan A, Ni Q, Huang Y, Gu S, et al. Age-Related Deterioration of Bone Toughness Is Related to Diminishing Amount of Matrix Glycosaminoglycans (GAGS). JBMR Plus (2018) 2(3):164-73. doi: 10.1002/jbm4.10030

227. Vizovišek M, Vidak E, Javoršek U, Mikhaylov G, Bratovš A, Turk B. Cysteine Cathepsins as Therapeutic Targets in Inflammatory Diseases. Expert Opin Ther Targets (2020) 24(6):573-88. doi: 10.1080/14728222.2020.1746765

228. von Bernhardi R, Eugenín-von Bernhardi L, Eugenín J. Microglial Cell Dysregulation in Brain Aging and Neurodegeneration. Front Aging Neurosci (2015) 7:124. doi: 10.3389/fnagi.2015.00124

229. Wendt W, Lübbert H, Stichel CC. Upregulation of Cathepsin S in the Aging and Pathological Nervous System of Mice. Brain Res (2008) 1232:7-20. doi: 10.1016/j.brainres.2008.07.067

230. Wendt W, Zhu XR, Lübbert H, Stichel CC. Differential Expression of Cathepsin X in Aging and Pathological Central Nervous System of Mice. Exp Neurol (2007) 204(2):525-40. doi: 10.1016/j.expneurol.2007.01.007

231. Effros RB, Dagarag M, Spaulding C, Man J. The Role of CD8+ T-Cell Replicative Senescence in Human Aging. Immunol Rev (2005) 205:147-57. doi: 10.1111/j.0105-2896.2005.00259.X

232. Yang X, Wang X, Lei L, Sun L, Jiao A, Zhu K, et al. Age-Related Gene Alteration in Naïve and Memory T Cells Using Precise Age-Tracking Model. Front Cell Dev Biol (2021) 8(1901). doi: 10.3389/fcell.2020.624380

233. Llorente L, Richaud-Patin Y, Díaz-Borjón A, Jakez-Ocampo J, Alvarado-De La Barrera C. Increased Collagenase and Dipeptidyl Peptidase I Activity in Leucocytes From Healthy Elderly People. Clin Exp Immunol (1999) 116 (3):425-9. doi: 10.1046/j.1365-2249.1999.00877.x

234. Sansoni P, Cossarizza A, Brianti V, Fagnoni F, Snelli G, Monti D, et al. Lymphocyte Subsets and Natural Killer Cell Activity in Healthy Old People and Centenarians. Blood (1993) 82(9):2767-73. doi: 10.1182/blood.V82. 9.2767.bloodjournal8292767

235. Boonen S, Rosenberg E, Claessens F, Vanderschueren D, Papapoulos S. Inhibition of Cathepsin K for Treatment of Osteoporosis. Curr Osteoporos Rep (2012) 10(1):73-9. doi: 10.1007/s11914-011-0085-9

236. Yasuda Y, Kaleta J, Brömme D. The Role of Cathepsins in Osteoporosis and Arthritis: Rationale for the Design of New Therapeutics. Adv Drug Deliv Rev (2005) 57(7):973-93. doi: 10.1016/j.addr.2004.12.013

237. Saegusa K, Ishimaru N, Yanagi K, Arakaki R, Ogawa K, Saito I, et al. Cathepsin S Inhibitor Prevents Autoantigen Presentation and Autoimmunity. J Clin Invest (2002) 110(3):361-9. doi: 10.1172/JCI0214682

238. Yan X, Wu C, Chen T, Santos MM, Liu CL, Yang C, et al. Cathepsin S Inhibition Changes Regulatory T-Cell Activity in Regulating Bladder Cancer and Immune Cell Proliferation and Apoptosis. Mol Immunol (2017) 82:6674. doi: 10.1016/j.molimm.2016.12.018

239. Lindahl C, Simonsson M, Bergh A, Thysell E, Antti H, Sund M, et al. Increased Levels of Macrophage-Secreted Cathepsin S During Prostate Cancer Progression in TRAMP Mice and Patients. Cancer Genomics Proteomics (2009) 6(3):149-59.

240. Gounaris E, Tung CH, Restaino C, Maehr R, Kohler R, Joyce JA, et al. Live Imaging of Cysteine-Cathepsin Activity Reveals Dynamics of Focal Inflammation, Angiogenesis, and Polyp Growth. PloS One (2008) 3(8): e2916-e. doi: 10.1371/journal.pone.0002916

241. Salpeter SJ, Pozniak Y, Merquiol E, Ben-Nun Y, Geiger T, Blum G. A Novel Cysteine Cathepsin Inhibitor Yields Macrophage Cell Death and Mammary
Tumor Regression. Oncogene (2015) 34(50):6066-78. doi: 10.1038/ onc. 2015.51

242. Oelschlaegel D, Weiss Sadan T, Salpeter S, Krug S, Blum G, Schmitz W, et al. Cathepsin Inhibition Modulates Metabolism and Polarization of TumorAssociated Macrophages. Cancers (2020) 12:2579. doi: 10.3390/ cancers12092579

243. Maekawa Y, Himeno K, Ishikawa H, Hisaeda H, Sakai T, Dainichi T, et al. Switch of CD4+ T Cell Differentiation From Th2 to Th1 by Treatment With Cathepsin B Inhibitor in Experimental Leishmaniasis. J Immunol (1998) 161 (5):2120-7.

244. Zhang T, Maekawa Y, Hanba J, Dainichi T, Nashed BF, Hisaeda H, et al. Lysosomal Cathepsin B Plays an Important Role in Antigen Processing, While Cathepsin D Is Involved in Degradation of the Invariant Chain Inovalbumin-Immunized Mice. Immunology (2000) 100(1):13-20. doi: 10.1046/j.1365-2567.2000.00000.x

245. Zhang T, Maekawa Y, Yasutomo K, Ishikawa H, Fawzy Nashed B, Dainichi T, et al. Pepstatin A-Sensitive Aspartic Proteases in Lysosome are Involved in Degradation of the Invariant Chain and Antigen-Processing in Antigen Presenting Cells of Mice Infected With Leishmania Major. Biochem Biophys Res Commun (2000) 276(2):693-701. doi: 10.1006/bbrc.2000.3538

246. Zhang T, Maekawa Y, Sakai T, Nakano Y, Ishii K, Hisaeda H, et al. Treatment With Cathepsin L Inhibitor Potentiates Th2-Type Immune Response in Leishmania Major-Infected BALB/c Mice. Int Immunol (2001) 13(8):975-82. doi: 10.1093/intimm/13.8.975

247. Bechara A, Barbosa CM, Paredes-Gamero EJ, Garcia DM, Silva LS, Matsuo AL, et al. Palladacycle (BPC) Antitumour Activity Against Resistant and Metastatic Cell Lines: The Relationship With Cytosolic Calcium Mobilisation and Cathepsin B Activity. Eur J Med Chem (2014) 79:24-33. doi: 10.1016/j.ejmech.2014.03.073

248. Chen Y, Li X, Boini KM, Pitzer AL, Gulbins E, Zhang Y, et al. Endothelial Nlrp3 Inflammasome Activation Associated With Lysosomal Destabilization During Coronary Arteritis. Biochim Biophys Acta (2015) 1853(2):396-408. doi: 10.1016/j.bbamcr.2014.11.012

249. Kreuzaler PA, Staniszewska AD, Li W, Omidvar N, Kedjouar B, Turkson J, et al. Stat3 Controls Lysosomal-Mediated Cell Death In Vivo. Nat Cell Biol (2011) 13(3):303-9. doi: 10.1038/ncb2171

250. Tschopp J, Schroder K. NLRP3 Inflammasome Activation: The Convergence of Multiple Signalling Pathways on ROS Production? Nat Rev Immunol (2010) 10(3):210-5. doi: 10.1038/nri2725

251. Chevriaux A, Pilot T, Derangère V, Simonin H, Martine P, Chalmin F, et al. Cathepsin B Is Required for NLRP3 Inflammasome Activation in Macrophages, Through NLRP3 Interaction. Front Cell Dev Biol (2020) 8 (167):1585-600. doi: 10.3389/fcell.2020.00167

252. Gicquel T, Robert S, Loyer P, Victoni T, Bodin A, Ribault C, et al. IL-1 $\beta$ Production Is Dependent on the Activation of Purinergic Receptors and NLRP3 Pathway in Human Macrophages. FASEB J (2015) 29(10):4162-73. doi: 10.1096/fj.14-267393

253. Luke CJ, Pak SC, Askew YS, Naviglia TL, Askew DJ, Nobar SM, et al. An Intracellular Serpin Regulates Necrosis by Inhibiting the Induction and Sequelae of Lysosomal Injury. Cell (2007) 130(6):1108-19. doi: 10.1016/ j.cell.2007.07.013

Conflict of Interest: The authors declare that the research was conducted in the absence of any commercial or financial relationships that could be construed as a potential conflict of interest.

Copyright (c) 2021 Perišić Nanut, Pečar Fonović, Jakoš and Kos. This is an openaccess article distributed under the terms of the Creative Commons Attribution License (CC BY). The use, distribution or reproduction in other forums is permitted, provided the original author(s) and the copyright owner(s) are credited and that the original publication in this journal is cited, in accordance with accepted academic practice. No use, distribution or reproduction is permitted which does not comply with these terms. 